\title{
Insights into the role of C3d dimers in B cell activation and Staphylococcal immune evasion
}

Wahid, A.A. ${ }^{1 *}$, Dunphy, R.W. ${ }^{1}$, Macpherson, A. ${ }^{1,2}$, Gibson, B.G. ${ }^{3}$, Kulik, L. ${ }^{4}$, Whale, K. ${ }^{2}$, Back, C.R. ${ }^{1}$, Hallam, T.M. ${ }^{3}$, Alkhawaja, B. ${ }^{5}$, Martin, R.L. ${ }^{5}$, Meschede, I.P. ${ }^{2}$, Lawson, A.D.G. ${ }^{2}$, Holers, V.M. ${ }^{4}$, Watts, A.G. ${ }^{5,6}$, Crennell, S.J. ${ }^{1}$, Harris, C.L. ${ }^{3}$, Marchbank, K.J. ${ }^{3}$ and van den Elsen, J.M.H. ${ }^{1,6^{*}}$.

${ }^{1}$ Department of Biology and Biochemistry, University of Bath, Bath, UK ${ }^{2}$ UCB Celltech, Slough, UK

${ }^{3}$ Translational and Clinical Research Institute, Newcastle University, Newcastleupon-Tyne, UK

${ }^{4}$ Division of Rheumatology, University of Colorado Anschutz Medical Campus, Aurora, Colorado, USA

${ }^{5}$ Department of Pharmacy and Pharmacology, University of Bath, Bath, UK

${ }^{6}$ Centre for Therapeutic Innovation, University of Bath, Bath, UK

"Corresponding author addresses: Ayla A. Wahid (A.A.Wahid@bath.ac.uk) and Jean M.H. van den Elsen (J.M.H.V.Elsen@bath.ac.uk)

\section{Abstract}

Cleavage of $\mathrm{C} 3$ to $\mathrm{C} 3 \mathrm{a}$ and $\mathrm{C} 3 \mathrm{~b}$ plays a central role in the generation of complement-mediated defences. Although the thioester-mediated surface deposition of $\mathrm{C} 3 \mathrm{~b}$ has been well-studied, fluid-phase dimers of $\mathrm{C} 3$ fragments remain largely unexplored. Here we present the first X-ray crystal structures of disulphide-linked human C3d dimers and show they undergo structurally-stabilising $\mathrm{N}$-terminal domain swapping when in complex with the Staphylococcus aureus immunomodulator Sbi. Through binding studies and flow cytometric analyses we uncover the physiologically-relevant roles of these dimers in crosslinking complement receptor 2 and modulating $B$ cell activation to potentially promote anergy. This potential induction of cellular tolerance by C3d dimers could contribute to Sbi-mediated $S$. aureus immune evasion as well as limit autoreactive immune responses under physiological conditions. Thus, insights gained from our findings could inform the design of novel therapies for autoimmune disorders and enhance our understanding surrounding the importance of complement in the fluid phase. 


\section{Introduction}

Activation of the central complement component C3 to C3a and C3b by classical/lectin $(\mathrm{C} 4 \mathrm{bC} 2 \mathrm{a})$ or alternative $(\mathrm{C} 3 \mathrm{bBb})$ pathway $\mathrm{C} 3$ convertases plays an essential role in the generation of complement-mediated defence mechanisms against invading microbial pathogens. While the circulating $\mathrm{C} 3 \mathrm{a}$ anaphylatoxin is involved in inducing inflammatory immune responses, C3b facilitates opsonophagocytosis and clearance of immune complexes through thioestermediated opsonisation of primary amine- or hydroxyl-containing antigenic and self surfaces. Attachment of multiple copies of C3b and its breakdown products to antigenic surfaces in this way can result in C3d-complement receptor 2 (CR2/CD21) and antigen-B cell receptor (BCR) co-ligation which generates co-stimulatory signals for $\mathrm{B}$ cell activation in a C3d copy-dependent manner ${ }^{1,2}$ and has been widely explored in vaccine design ${ }^{3-8}$.

Structure determination of native C3, C3b and C3c has provided crucial insights into the mechanistic basis behind the activation of $\mathrm{C} 3$ to $\mathrm{C} 3 \mathrm{~b}^{9,10}$ while complexes of $\mathrm{C} 3 \mathrm{~b}$ with factor I (FI) and the short consensus repeat (SCR) domains 1-4 of its cofactor factor $\mathrm{H}\left(\mathrm{FH}_{1-4}\right)$ have revealed the processes through which $\mathrm{C} 3 \mathrm{~b}$ is proteolytically cleaved into its successive opsonin fragments $\mathrm{iC} 3 \mathrm{~b}$ and $\mathrm{C} 3 \mathrm{dg}^{11}$. Crystal structures have also shed light upon the molecular basis underlying the thioester-mediated attachment of $\mathrm{C} 3 \mathrm{~d}$ to antigenic surfaces ${ }^{12}$, provided explanations of how the interactions of $\mathrm{C} 3 \mathrm{~d}$ with its receptors $\left(\mathrm{CR} 2^{13}\right.$ and $\left.\mathrm{CR} 3^{14}\right)$ facilitate the recognition of opsonised antigens, and the mechanisms by which pathogens such as Staphylococcus aureus utilise C3d-binding proteins (e.g. Sbi ${ }^{15}$, Efb-C ${ }^{16,17}$ and $\mathrm{Ecb} / \mathrm{Ehp}^{18,19}$ ) to inhibit these interactions and evade the immune system. Furthermore, complexes of C3d with FH SCR domains 19 and 20 have been pivotal in understanding the regulatory measures in place to protect host tissues against the indiscriminate attachment of C3d to self versus non-self surfaces ${ }^{20,21}$.

However, while these seminal structural studies alongside an abundance of functional investigations have advanced our knowledge surrounding the interaction of C3 fragments with self and non-self surfaces at a molecular level, our understanding of the structural and functional aspects of fluid phase C3 activation 
products remains incomplete. During activation in the fluid phase, most of the C3 molecules do not covalently attach to surface-exposed hydroxyl- or aminenucleophiles but instead the highly reactive Cys-GIn thioester moiety within the thioester-containing C3d domain (TED) of C3 undergoes hydrolysis resulting in the generation of $\mathrm{C} 3\left(\mathrm{H}_{2} \mathrm{O}\right)$ and formation of the $\mathrm{C} 3\left(\mathrm{H}_{2} \mathrm{O}\right) \mathrm{Bb}$ alternative pathway (AP) C3 convertase. Only approximately $10 \%$ of C3b $\left(\sim 1 \mathrm{mg} \mathrm{mL}^{-1}\right)$ generated by these fluid phase or surface-associated convertases is deposited onto reactive surfaces ${ }^{22}$, leaving the remaining $90 \%$ to react with water wherein exposure of the cysteine free sulfhydryl can lead to dimerisation of C3b and its subsequent breakdown products $^{23,24}$.

Disulphide or thioester-linked C3b dimers ${ }^{25}$ have been found to bind CR1 with 25fold higher affinity than monomeric $\mathrm{C}_{3} \mathrm{~b}^{26}$, induce histaminase release from human polymorphonuclear leukocytes ${ }^{27}$, serve as binding platforms for factor $\mathrm{B}$ fragment $\mathrm{Bb}$ during formation of AP C5 convertases ${ }^{28,29}$ and act as potent AP activators in complex with $\lg \mathrm{G}^{30}$. Dimers of C3dg have also been isolated from C3-activated human serum following omission of $\mathrm{N}$-ethylmaleimide ${ }^{31}$ and the propensity of recombinant $\mathrm{C} 3 \mathrm{~d}$ to dimerise has been reported previously ${ }^{32,33}$. A crystal structure of dimeric C3dg purified from rat serum ${ }^{34}$ provides further crucial evidence of the endogenous existence of these dimers. However, aside from this severely truncated C3dg dimer which is believed to have undergone proteolytic truncation during the crystallisation process ${ }^{35}$, there is currently a gap in knowledge surrounding the structural significance of disulphide-linked dimers of C3 fragments as the thioester cysteine sulfhydryl is routinely removed prior to structural analyses. For instance, the free cysteine of $\mathrm{C} 3 \mathrm{~b}$ has been reacted with iodoacetamide prior to structural determination ${ }^{10,36,37}$ and the vast majority of C3d constructs used for structural studies to date have harboured a cysteine to alanine substitution in order to prevent dimerisation ${ }^{12,13,20,21}$.

In this study we therefore aimed to delineate the molecular details and explore the functional significance of dimeric human C3 fragments that can form following activation of C3 in the fluid phase. We present the first crystal structure of a human C3d dimer at $2.0 \AA$ where dimerisation is mediated by disulphide linkage of the thioester cysteine residues. In addition, through X-ray crystallography, we show this 
C3d dimer undergoes structurally-stabilising N-terminal 3D domain swapping when bound to domain IV of the $S$. aureus C3-activating immune evasion protein Sbi, thereby providing the first example of this ligand-induced structural phenomenon in a complement protein. Through surface plasmon resonance (SPR) binding studies and cell experiments using mouse splenocytes and human PBMC we show how dimeric C3d crosslinks surface-bound CR2 and can modulate B cell activation to promote the establishment of tolerance/anergy by downregulating CD40 in a more robust manner than C3d monomers. Thus, in the future these newly-discovered physiologically-relevant roles of C3 fragment dimers could inform the design of autoimmune therapies and help to further elucidate the significance of complement in the fluid phase as it interacts with cells of the adaptive immune system and beyond. 


\section{Results}

In order to elucidate the importance of dimeric human C3 fragments, here we determined the crystal structures of disulphide-linked human C3d dimers in the absence or presence of Sbi domain IV. Following SPR studies comparing the binding kinetics and avidity of dimeric and monomeric C3d, C3d-induced changes in the activation state of $B$ cells were explored using flow cytometric analyses.

\section{Disulphide linkage of the thioester cysteine results in C3d dimerisation}

A crystal structure of wild-type human C3d, harbouring a cysteine at position 17/1010 (C3d numbering/intact pre-pro C3 numbering) (C3 $\mathrm{d}^{17 \mathrm{C}}$ ), was obtained at 2.0 $\AA ̊$ resolution (Figure 1, Supplementary Tables S1 and S2). The structure clearly shows the formation of a dimer mediated by partial disulphide linkage of the thioester cysteine residues at position $17 / 1010$ in both monomeric chains. This $17 \mathrm{C}-17 \mathrm{C}$ disulphide creates a link between the two C3d monomers at the C-terminus of helix $\alpha 1$, causing the convex molecular surfaces of the monomers to orient towards each other whilst simultaneously exposing their concave binding faces (Figure 1a). Closer examination of the $\mathrm{C} 3 \mathrm{~d}^{17 \mathrm{C}}$ dimer interaction surface (Figure 1b) confirms that the overall $(\alpha-\alpha)_{6}$ barrel configuration of both monomers remains unchanged and comparable to previously-published structures of monomeric C3d (0.61 $\AA$ (chain A)/0.40 A (chain B) main chain (M1-P294) RMSD relative to PDB: 1C3D). The 2FoFc electron density map at the $C 3 d^{17 C}$ dimer interface shows that chain $B$ residue 17C (Figure 1b inset) adopts a dual conformation with one conformer existing in an unpaired oxidized form. This indicates the disulphide bond linking the two C3d monomers can occur in a partially disconnected state which is consistent with results from size exclusion chromatography experiments suggesting $C 3 d^{17 C}$ exists in a monomer-dimer equilibrium in solution (Supplementary Figure S1). 


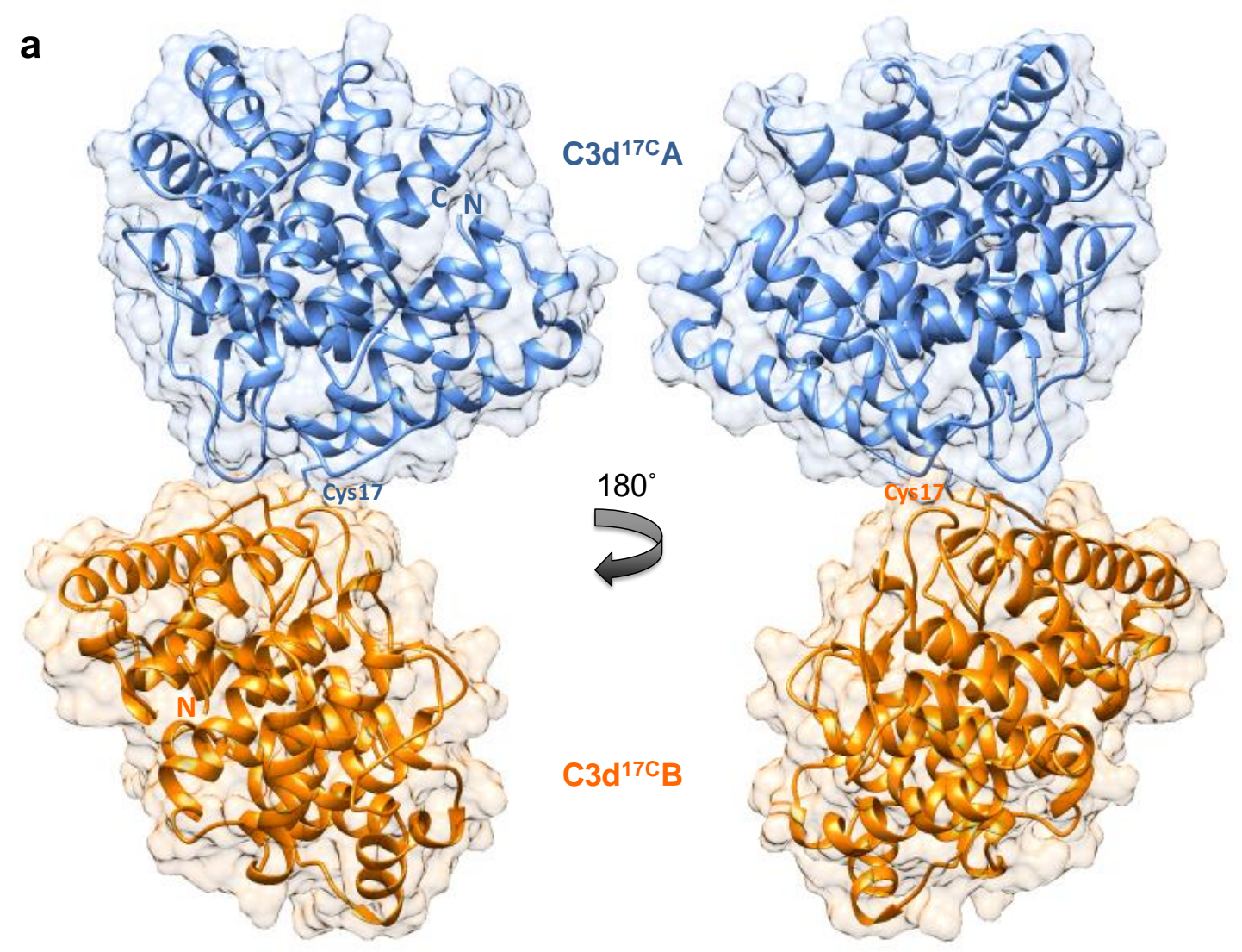

b

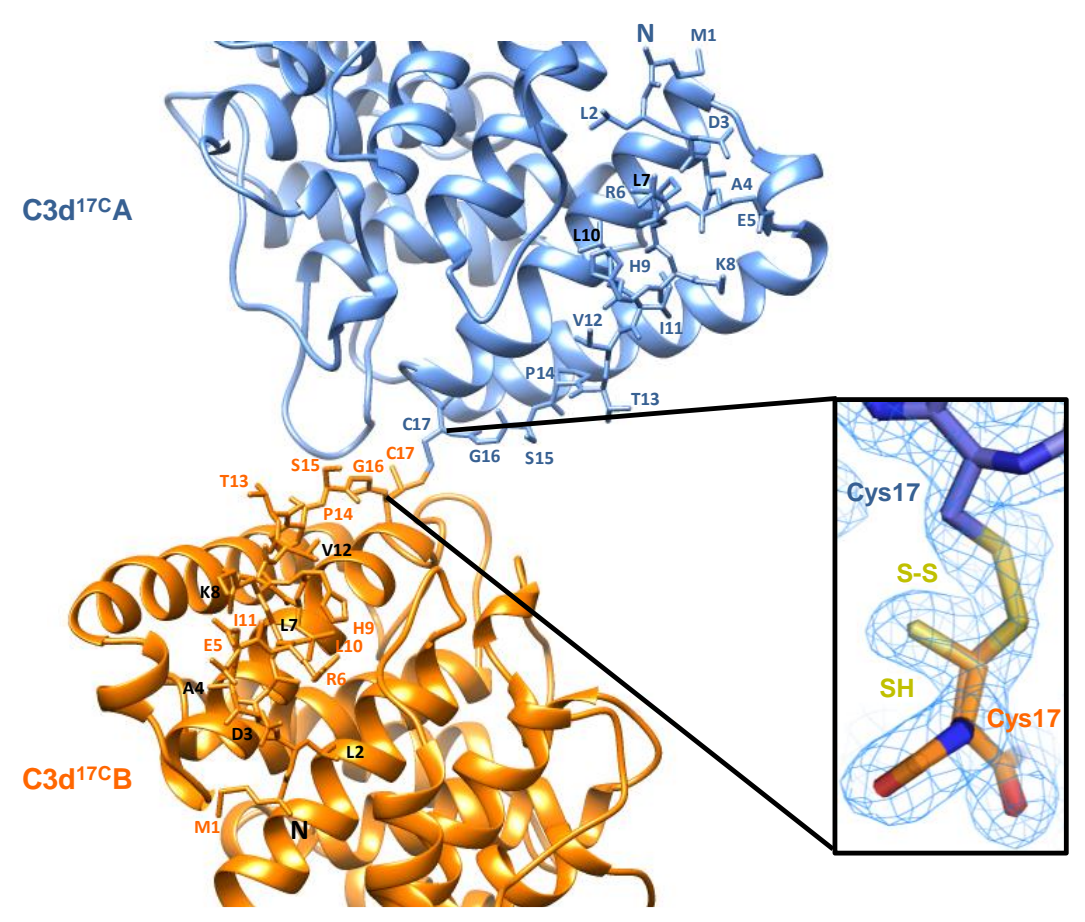

Figure 1. Structure of a disulphide-linked human $\mathrm{C} 3 \mathrm{~d}^{17 \mathrm{C}}$ dimer at $2.0 \AA$ 年esolution. (a) The ribbon diagram shows disulphide linkage of the monomeric subunits at position Cys 17 results in the formation of a dimer $92.37 \AA$ in length with a $0.61 \AA$ (chain A)/0.40 A (chain B) main chain (M1-P294) RMSD relative to the structure of $C 3 d^{17 A}$ (PDB:1C3D). (b) Enlarged view of the $C 3 d^{17 C}$ dimer interface showing the side chains of helix a1 residues M1-C17. Inset: electron density contoured at $1.0 \sigma$ of the partially broken $\mathrm{C} 17-\mathrm{C} 17$ interchain disulphide bond $(2.07 \AA)$ resulting from oxidation of one conformer of Chain B Cys17. PDB submission code: 6RMT. See Supplementary Tables S1 and S2 for data collection and refinement statistics. 
Superimposition of the ligand-binding domains of CR2 (SCR1-2), the $\mathrm{am}_{\mathrm{M}}$ integrin domain of CR3 or SCRs 19-20 of FH on to the dimeric C3d ${ }^{17 C}$ structure fails to generate any molecular clashes (Supplementary Figures S2a-d). This important observation suggests dimerisation does not cause any interference in the formation of complexes between C3d or C3dg and their most physiologically-relevant binding partners. Staphylococcus aureus immune evasion proteins such as Efb-C, Ecb/Ehp and Sbi-IV are also predicted to bind the $\mathrm{C} 3 \mathrm{~d}^{17 \mathrm{C}}$ dimer without any hindrance as the concave surfaces of both monomers are exposed and accessible. Significantly, as CR2 and CR3 interact with the C3d ${ }^{17 C}$ dimer via opposing surfaces, complement receptor crosslinking could play an important role in the function of $\mathrm{C} 3 \mathrm{~d}$ dimers (Supplementary Figure S2a-c). Moreover, the absence of steric hindrance following superimposition of the $\mathrm{C} 3 \mathrm{~d}^{17 C}$ dimer onto the C3b TED domain (Supplementary Figure S2e), suggests dimerisation of C3b, as proposed previously ${ }^{23,24}$, could occur in a similar fashion to $\mathrm{C} 3 \mathrm{~d}$ without affecting the ability of $\mathrm{C} 3 \mathrm{~b}$ to interact with the complement regulators $\mathrm{FH}$ and $\mathrm{FI}$.

\section{Sbi-IV induces $\mathrm{N}$-terminal helix swapping of dimeric C3d}

Following on from our structural analyses of the $\mathrm{C} 3 \mathrm{~d}^{17 \mathrm{C}}$ dimer alone, we used cocrystallisation to determine the structure of a complex between C3d ${ }^{17 C}$ and Sbi-IV at $2.4 \AA$ (Figure 2, Supplementary Tables S1 and S2) in the interests of gaining an understanding of how dimeric C3d(g) could be exploited by pathogens such as $S$. aureus to modulate immune responses. Previous studies have shown Sbi-IV, which adopts a three-helix bundle fold ${ }^{38}$, binds the acidic residue-lined concave face of C3d ${ }^{15}$ and together with Sbi domain III can be harnessed as a vaccine adjuvant that promotes the opsonisation of antigens with a 'natural' coat of C3 breakdown products $^{8}$ via AP activation-mediated consumptive cleavage of $\mathrm{C}^{39}$.

The C3 $d^{17 C}$-Sbi-IV complex presented here shows both the opposing concave binding surfaces of the $\mathrm{C} 3 \mathrm{~d}^{17 \mathrm{C}}$ dimer are occupied by domain IV of the Sbi immune evasion protein (Figure 2a) in the same manner observed previously by Clark and colleagues ${ }^{15}$. In our structure, occlusion caused by the tight dimer interactions prevents secondary binding of Sbi-IV to the convex surface of C3d close to the thioester region described in the same study (Supplementary Figure S3). In clear 
contrast to the unliganded C3 ${ }^{17 C}$ dimer shown in Figure 1a, the C3d ${ }^{17 C}$ dimer bound to Sbi-IV has undergone a helix swap, a relatively rare structural manifestation whereby a reciprocal exchange between the identical $\mathrm{N}$-terminal $\alpha 1$ helices of the two C3d chains has occurred (Figure 2a). As depicted in Figure 2b, the helix a1 region M1/994 - G16/1009, located N-terminally from C17/1010, has undergone a full $3 \mathrm{D}$ domain swap in both $\mathrm{C} 3 \mathrm{~d}^{17 \mathrm{C}}$ molecules, recreating identical interactions with the opposing C3d recipient without causing appreciable differences in relative orientation $(0.80 \AA$ (chain $A) / 0.76 \AA$ (chain $B$ ) main chain (G16-P294) RMSDs relative to PDB: 1C3D) (Figure 3). The fact that the swap is found to occur at a neutral $\mathrm{pH}$ of 8 rather than the acidic $\mathrm{pH}$ (3.5-4.0) known to induce domain swapping in other proteins ${ }^{40}$, provides support for its physiological relevance. Unlike the unliganded $\mathrm{C} 3 \mathrm{~d}^{17 \mathrm{C}}$ dimer, the $2 \mathrm{Fo}-\mathrm{Fc}$ electron density map of dimeric $\mathrm{C} 3 \mathrm{~d}^{17 \mathrm{C}}$ in the Sbi-IV bound state distinctly shows the formation of two alternative 17C-17C inter-chain disulphide bond configurations at the C3d dimer interface that both remain intact (Figure 2b inset).

\section{Helix swapping structurally stabilises dimeric C3d}

In addition to stabilising the 17C-17C inter-chain disulphide, the helix $\alpha 1$ swap causes a substantial increase (617\%) in joint buried surface area from $720.6 \AA^{2}$ in the $C 3 d^{17 C}$ dimer to $4445.4 \AA^{2}$ in the Sbi-IV-bound helix-swapped C $3 d^{17 C}$ dimer. This expansion in interface area is supported by molecular interactions including 14 hydrogen bonds and 4 ionic interactions which are absent in the unliganded dimer. Of note, the exact region (M1/994 - G16/1009) located at the extreme N-terminus of C3 $d^{17 C}$ involved in helix swapping as well as the $17 \mathrm{C}-17 \mathrm{C}$ inter-chain disulphide is absent in the structure of the truncated rat C3d dimer crystallised following proteolytic breakdown of C3dg purified from serum ${ }^{34}$. It is therefore possible the helix swap observed here buries the newly-exposed surface prior to a further degradation step, producing a more compact C3d dimer, C3dt. 
a

a

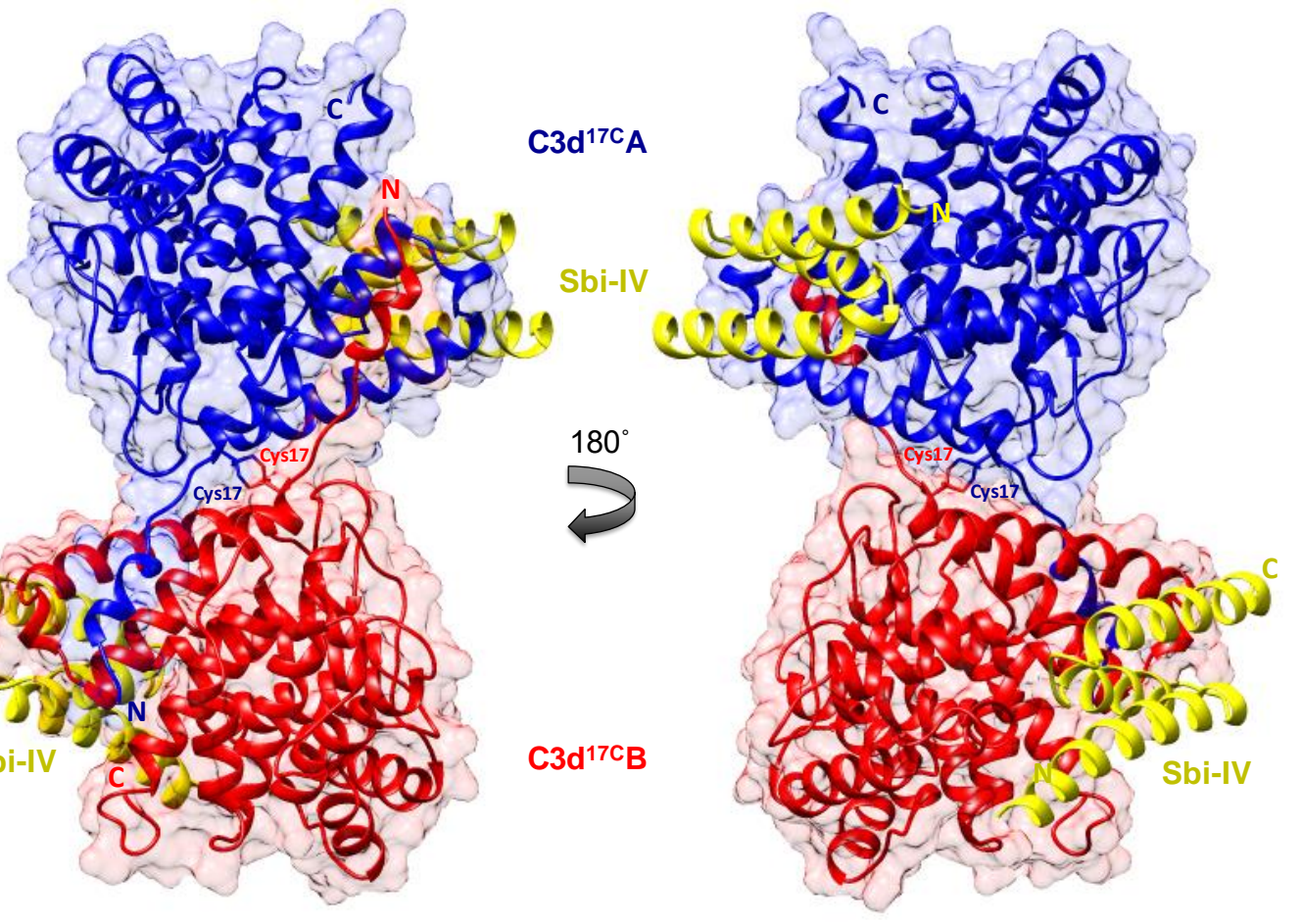

b

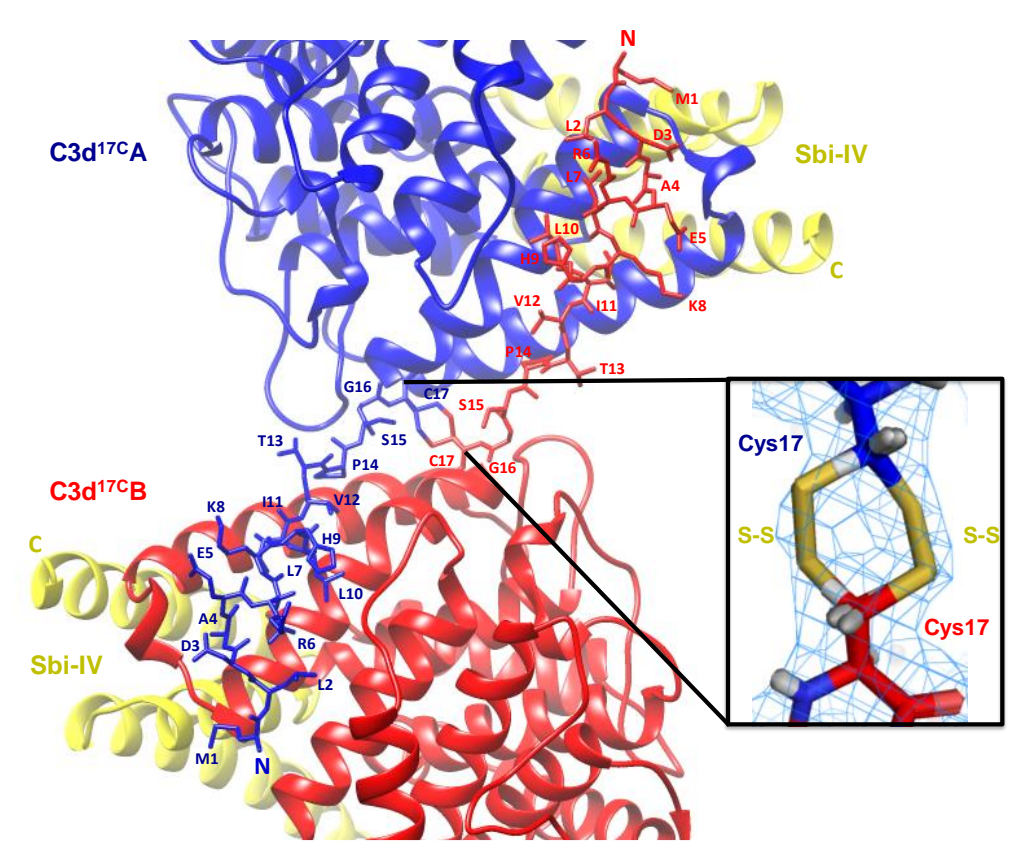

Figure 2. Structure of an $\mathrm{N}$-terminal helix-swapped human $\mathrm{C} 3 \mathrm{~d}^{17 \mathrm{C}}$ dimer in complex with Sbi-IV at 2.4 A resolution. (a) In addition to a C17-C17 disulphide linkage, the ribbon diagrams show reciprocal swapping of the $\mathrm{N}$-terminal $\alpha 1$ helix region $\mathrm{M} 1-\mathrm{G} 16$ between the two $\mathrm{C} 3 \mathrm{~d}$ chains resulting in a domain-swapped dimeric complex $92.31 \AA$ in length with a $0.80 \AA$ (chain $A$ ) $/ 0.76 \AA$ (chain $B$ ) main chain (G16-P294) RMSD relative to the structure of C3d ${ }^{17 A}$ (PDB:1C3D). (b) Enlarged view of the C3d ${ }^{17 C}$ dimer interface when in complex with Sbi-IV showing side chains of the swapped helix $\alpha 1$ region. Inset: electron density contoured at $1.0 \sigma$ of two possible $\mathrm{C} 17-\mathrm{C} 17$ interchain disulphide bonds resulting from dual conformation of Chain $A$ and Chain $B$ residue Cys17 (Chain $A$ C17 conformer $A$ Chain B C17 conformer A: $2.04 \AA$, Chain A C17 conformer B-Chain B C17 conformer B: $2.06 \AA$ ) with a preference for the conformer B disulphide (Chain B C17 conformer B occupancy: 0.66). PDB submission code: 6RMU. See Supplementary Tables S1 and S2 for data collection and refinement statistics. 
Further evidence of an Sbi-IV-induced stabilisation effect was also acquired through near-UV (320-250 nm) circular dichroism (CD) spectroscopic analyses of C3d collected as a function of temperature where the absorption of aromatic side chains and disulphide bonds, absent in Sbi-IV, provides information about the protein's tertiary structure ${ }^{41}$ (Supplementary Figure S4). Here, Sbi-IV was found to significantly increase the melting temperature $(\Delta \mathrm{Tm})$ of $\mathrm{C} 3 \mathrm{~d}^{17 \mathrm{C}}$ by $8.7^{\circ} \mathrm{C}$ from $50.98 \pm$ $1.41^{\circ} \mathrm{C}$ in the absence of Sbi-IV (Supplementary Figure S4a) to $59.67 \pm 1.65^{\circ} \mathrm{C}$ in the presence of Sbi-IV (Supplementary Figure S4b), suggesting that Sbi-IVmediated helix swapping also enhances the structural stability of dimeric C3d ${ }^{17 C}$ in solution. Although Sbi-IV also raises the $\Delta \mathrm{Tm}$ of $\mathrm{C} 3 \mathrm{~d}^{17 \mathrm{~A}}$ by $\sim 9.0^{\circ} \mathrm{C}$, monomeric C3 $d^{17 A}$ is less thermally stable (Supplementary Figure S5a) and unlike dimeric C3 $d^{17 C}$ undergoes precipitation at temperatures above $65^{\circ} \mathrm{C}$ in the presence of wildtype Sbi-IV (Supplementary Figures S5b) but not with an N-terminally truncated Sbi-IV mutant (V1_D11del) lacking key residues that were shown to interact with helix $\alpha 1$ on the convex surface of C3d in the crystal structure and NMR analysis of the Sbi-IV:C3d ${ }^{17 A}$ complex $^{15}$ (Supplementary Figure S5c). This precipitation of C3 $d^{17 A}$ in the presence of wild-type Sbi-IV, and lack of it in the presence of the Sbi-IV truncation mutant V1_D11del, suggests that the potential displacement of the Nterminal $\alpha 1$ helical region of C3d in the absence of close C3d dimer interactions destabilises the three-dimensional structure of C3d, leading to aggregation and precipitation (see Supplementary Figures S4c and S5d for sigmoidal fits of thermal denaturation curves used for Tm calculations and Supplementary Figure S6 for C3 $d^{17 C}$ and C3 $d^{17 A}$ far-UV secondary structure analysis). 

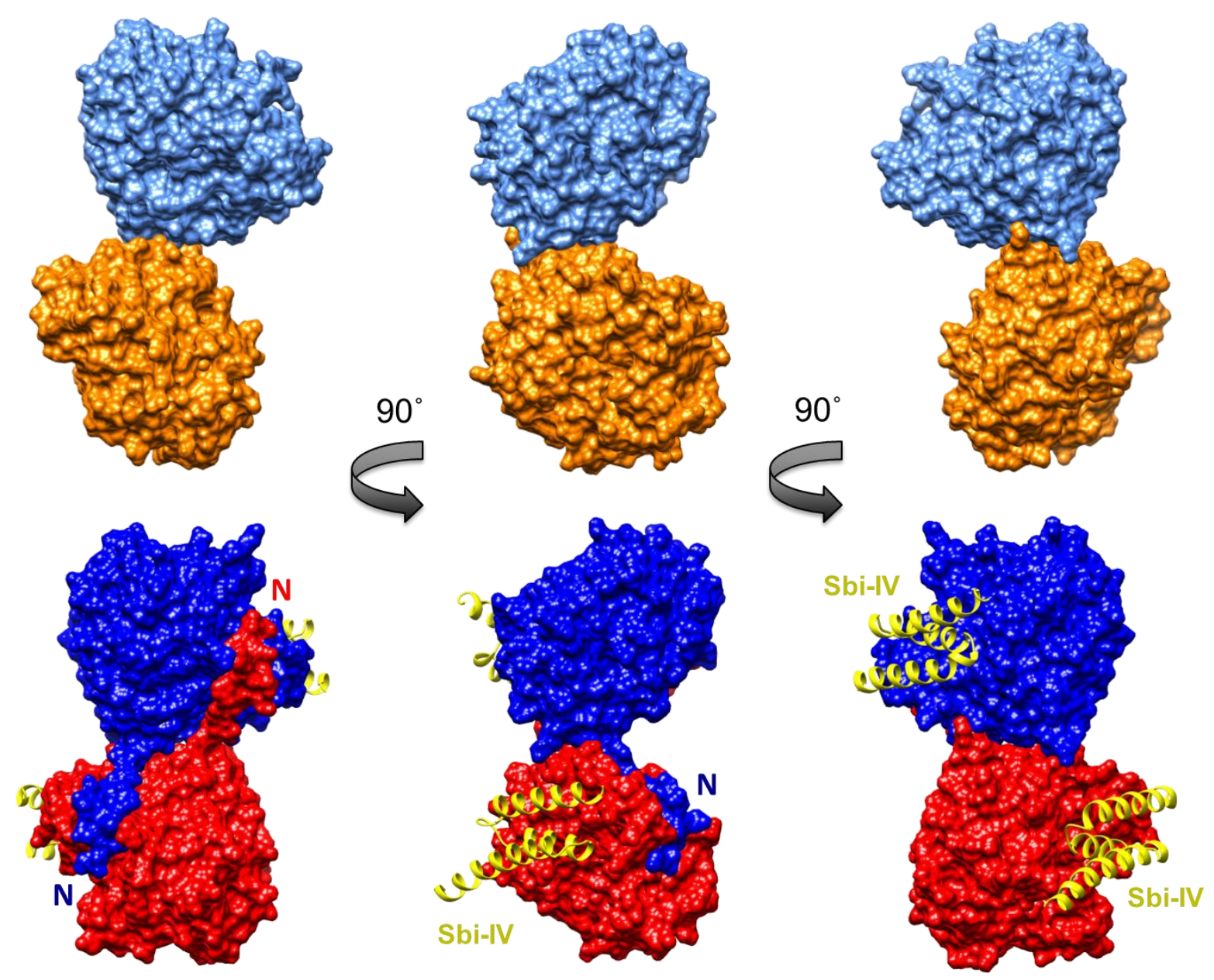

Figure 3. Molecular surface comparison of the $C 3 \mathbf{d}^{17 \mathrm{C}}$ dimer (top) and the $\mathbf{C} 3 \mathbf{d}^{17 \mathrm{C}}$ dimer in complex with Sbi-IV (bottom). Solid molecular surface representations in three different orientations rotated by $90^{\circ}$ angles counter-clockwise are shown where the $\mathrm{N}$-terminal helix swap can be seen in the C3d ${ }^{17 C}$ dimer-Sbi-IV complex.

\section{C3d dimers can crosslink CR2 and $\mathrm{FH}_{19-20}$}

As our structural analyses revealed the propensity of $C 3 d^{17 C}$ to dimerise, we next analysed the binding interactions of C3d dimers in comparison to monomeric C3d ${ }^{17 A}$ using $\mathrm{CR} 2$ and $\mathrm{FH}_{19-20}$ as two important known binding partners. Given that both the crystal structure of dimeric $\mathrm{C} 3 \mathrm{~d}^{17 \mathrm{C}}$ (Figure $\mathbf{1 b}$ inset) and size exclusion chromatography experiments (Supplementary Figure S1) showed the inter-chain disulphide bond at the dimer interface to be inherently unstable, chemical conjugation of the two $\mathrm{C} 3 \mathrm{~d}^{17 \mathrm{C}}$ monomers at position $17 \mathrm{C}$ through use of a brominebased linear linker (N,N'-(propane-1,3-diyl) bis(2-bromoacetamide)) was employed to create a more stable dimer amenable to purification (see Materials and Methods;

Supplementary Figures S7-S9b). The N,N'-(propane-1,3-diyl) bis(2- 
bromoacetamide) linker was used as this class of chemical compound has been shown to selectively crosslink cysteine residues located within close spatial proximity $^{42}$. Dimeric $\mathrm{C} 3 \mathrm{~d}^{17 \mathrm{C}}$ resulting from this chemical crosslinking reaction was subsequently validated using particle analysis (Supplementary Figure S9c), analytical ultracentrifugation (Supplementary Figure S9d) and mass spectrometry (Supplementary Tables S3 and S4, Supplementary Figure 9e) and utilised in SPR spectroscopy studies to gain insights into its binding patterns and kinetics.

In contrast to monomeric $\mathrm{C} 3 \mathrm{~d}^{17 \mathrm{~A}}$ which displays a conventional association-steady state-dissociation binding pattern when flowed over surface-immobilised CR2-Fc and $\mathrm{FH}_{19-20}$, the binding of dimeric $\mathrm{C} 3 \mathrm{~d}^{17 \mathrm{C}}$ to the same ligands was found to be noticeably distinct and suggestive of a two-state binding interaction (Figure 4a). At low concentrations up to the first replicate of $15.63 \mathrm{nM}$ (dashed line), the highly avid interactions with negligible dissociation indicate a bivalent binding mode whereby the C3d ${ }^{17 C}$ dimer crosslinks two $\mathrm{CR} 2-\mathrm{Fc}$ or two $\mathrm{FH}_{19-20}$ molecules. During the first injection of $15.63 \mathrm{nM} \mathrm{C} 3 \mathrm{~d}^{17 \mathrm{C}}$ dimer, $25 \mathrm{RU}$ of material binds to the surface and 10 $\mathrm{RU}$ remain avidly bound to the surface after the regeneration. While at the second $15.63 \mathrm{nM}$ injection, $18 \mathrm{RU}$ of material binds to the surface and only $2 \mathrm{RU}$ remains avidly bound at the end (Supplementary Figure S10). In both cases an equivalent amount of material is eluted during regeneration illustrating that the first injection likely saturates the highly avid binding sites. As the surface cannot be fully regenerated of these high avidity complexes, the subsequent cycle commences at a higher baseline response. At this point and higher concentrations, the high avidity binding sites for dimeric $\mathrm{C} 3 \mathrm{~d}^{17 \mathrm{C}}$ on $\mathrm{CR} 2-\mathrm{Fc}$ or $\mathrm{FH}_{19-20}$ remain saturated causing the binding mode to switch to less favourable/avid readily-disrupted interactions suggestive of $1: 1$ binding between the $\mathrm{C}^{2} \mathrm{~d}^{17 \mathrm{C}}$ dimer and $\mathrm{CR} 2-\mathrm{Fc}$ or $\mathrm{FH}_{19-20}$ although some cross-linked $\mathrm{C}^{3} \mathrm{~d}^{17 \mathrm{C}}$ dimer-CR2-Fc and $\mathrm{C} 3 \mathrm{~d}^{17 \mathrm{C}}$ dimer- $\mathrm{FH}_{19-20}$ complexes persist (1-2 RU of material remaining bound to the surface after regeneration). At the highest three concentrations of dimeric $\mathrm{C}^{3} \mathrm{~d}^{17 \mathrm{C}}(62.5-250 \mathrm{nM})$, the less favourable interactions which are readily eluted from the surface dominate (Figure 4a inset). Consistent with these results, the unusual binding patterns observed here were also evident in a further two independent experiments (Supplementary Figure S11) and cannot be attributed to higher order species of analyte or ligand as the biophysical techniques performed showed the dimeric $\mathrm{C}_{3} \mathrm{~d}^{17 \mathrm{C}}$ and $\mathrm{FH}_{19-20}$ preparations used did 
not contain aggregates (Supplementary Figures S9c, S9d and S12). Models illustrating the binding events described here are presented in Figure $\mathbf{4 b}$ (for CR2$\mathrm{Fc}$ ) and Figure 4c (for $\mathrm{FH}_{19-20)}$.

\section{Dimeric $\mathbf{C} 3 \mathrm{~d}$ is a more potent modulator of $\mathrm{B}$ cell activation than monomeric C3d}

Following on from our SPR studies, which indicated dimeric C3d may have the capacity to crosslink CR2, our next aim was to analyse the effects of dimeric compared to monomeric C3d on B cell activation. Flow cytometry was employed to examine changes in the expression of four surface-associated $\mathrm{B}$ cell activation markers (CD40, CD69, CD71 and CD86) resulting from stimulation of isolated human $B$ cells with monomeric C3 $d^{17 A}$ or chemically-linked dimeric $C 3 d^{17 C}$ alone or in the presence of BCR-crosslinking anti-IgM F(ab')2. As shown in Supplementary Figure S13, although agonism of the BCR by anti-IgM significantly enhances expression of all the activation markers (except CD40), neither monomeric C3d ${ }^{17 A}$ nor dimeric $\mathrm{C} 3 \mathrm{~d}^{17 \mathrm{C}}$ appears to influence the activation of isolated $\mathrm{B}$ cells in an appreciable manner, as measured by the markers examined.

A more general approach, using $\mathrm{Ca}^{2+}$ influx as a measure of $\mathrm{B}$ cell activation was therefore taken next. Here, incubation of $\mathrm{B} 220^{+}$mouse splenocytes with monomeric $\mathrm{C} 3 \mathrm{~d}^{17 \mathrm{~A}}$ or dimeric $\mathrm{C} 3 \mathrm{~d}^{17 \mathrm{C}}$ prior to stimulation with a suboptimal dose of a biotinylatedanti-lgM/C3dg-biotin/streptavidin (a-IgM-b/C3dg-b/ST) BCR/CR2-crosslinking complex was found to inhibit BCR/CR2-mediated $\mathrm{Ca}^{2+}$ influx in a concentrationdependent manner (Supplementary Figure S14). The observed blocking effect was more pronounced following treatment with dimeric $\mathrm{C} 3 \mathrm{~d}^{17 \mathrm{C}}$, particularly at the lower concentration of $4 \mu \mathrm{g}$ (Supplementary Figure S14a), and for both constructs is only evident when C3d is added ahead of the a-IgM-b/C3dg-b/ST complex and when a suboptimal dose of anti-lgM (i.e. unable to trigger $\mathrm{Ca}^{2+}$ influx in the absence of $\mathrm{CR} 2$ engagement) within the crosslinking complex is used. Thus, the perceived inhibition of $\mathrm{Ca}^{2+}$ influx and hence $\mathrm{B}$ cell activation is likely to result from sequestration of CR2 by monomeric $\mathrm{C} 3 \mathrm{~d}^{17 \mathrm{~A}}$, and to a greater extent, due to avidity and possibly via CR2CR2 crosslinking as suggested by our SPR experiments, dimeric C3d ${ }^{17 C}$, reducing the proportion of CR2 available for crosslinking with the BCR. 
a

\section{$\underline{\text { C3d } 17 A}$}
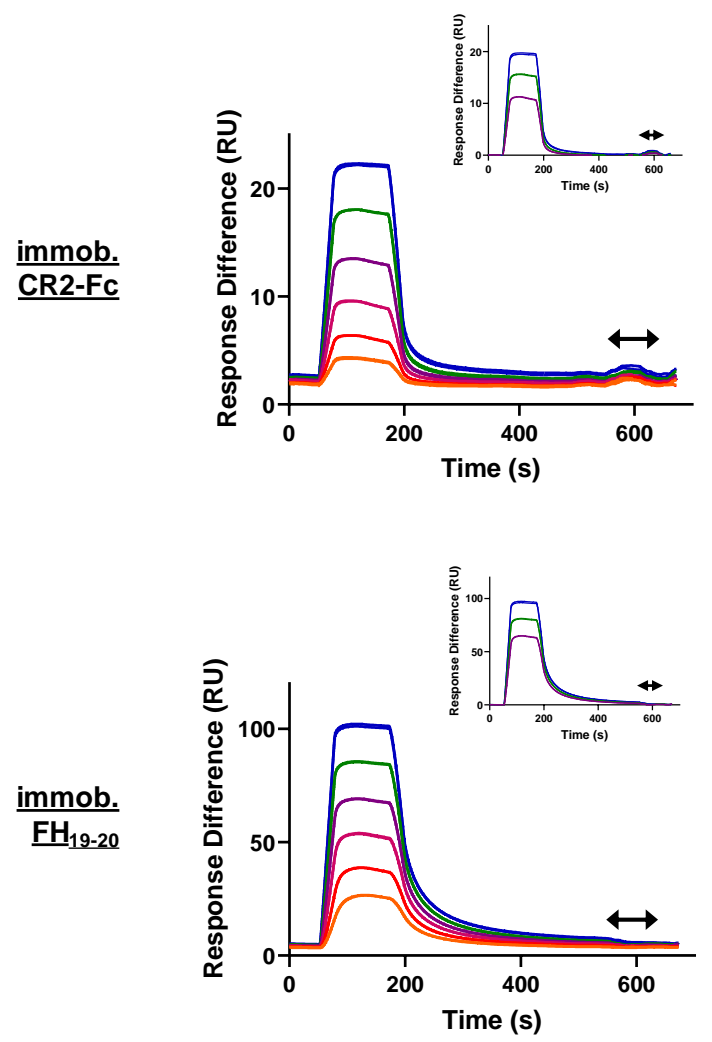

b
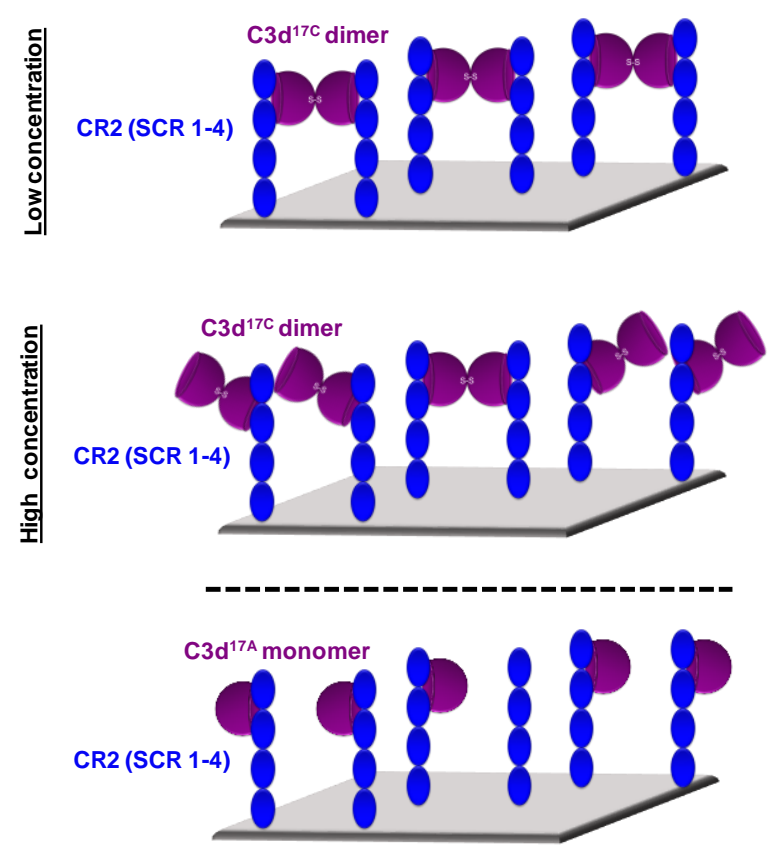

$\underline{\text { C3d }}{ }^{17 C}$ dimer
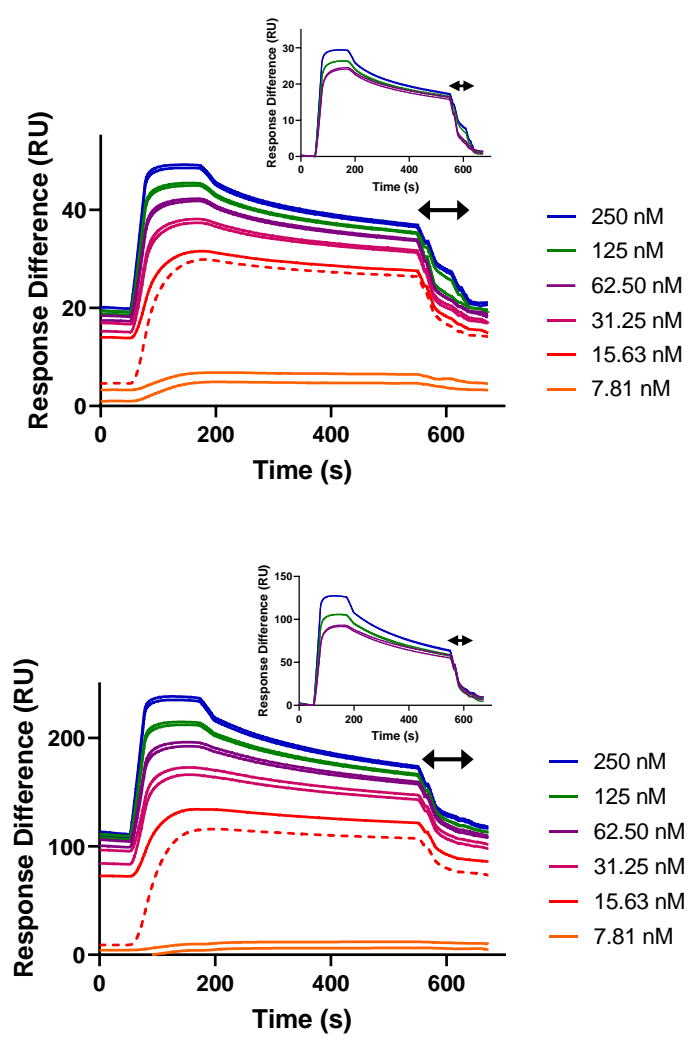

C
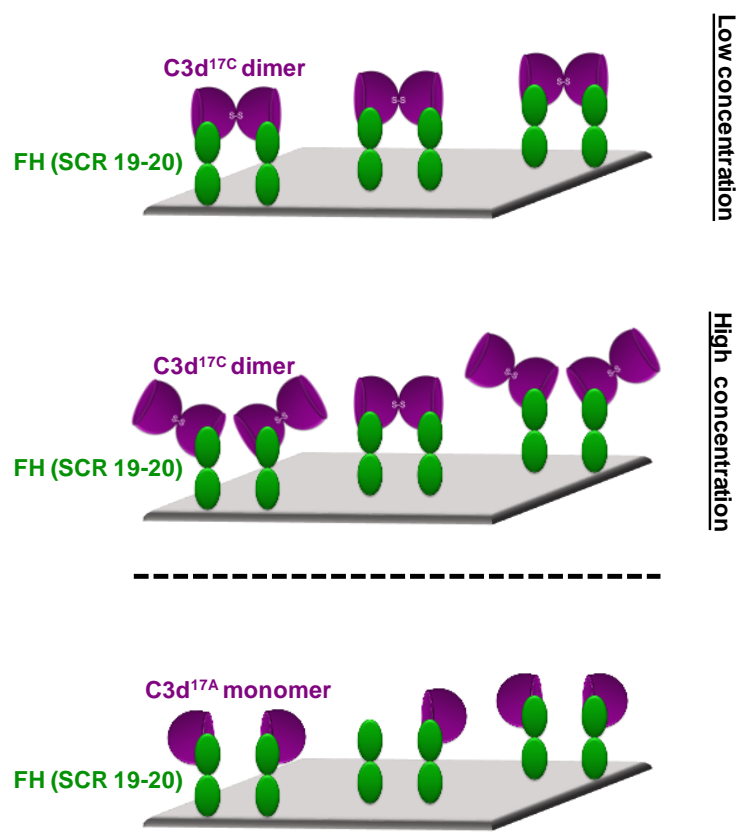

Figure 4. Dimeric $\mathrm{C} \mathrm{d}^{17 \mathrm{C}}$ crosslinks $\mathrm{CR2}$ and $\mathrm{FH}_{19-20 .}$ (a) SPR sensorgrams showing serially-diluted concentrations of $250 \mathrm{nM}$ monomeric C3d ${ }^{17 \mathrm{~A}}$ (left) or dimeric $\mathrm{C} 3 \mathrm{~d}^{17 \mathrm{C}}$ (right) flowed in duplicate over flow cells of a CM5 senor chip immobilised with $\mathrm{CR} 2-\mathrm{Fc}$ (top) or $\mathrm{FH}_{19-20}$ (bottom). The binding of $\mathrm{C} 3 \mathrm{~d}^{17 \mathrm{~A}}$ to $\mathrm{CR} 2-\mathrm{Fc}$ and $\mathrm{FH}_{19-20}$ follows a conventional association-steady state-dissociation pattern while the binding of dimeric $\mathrm{C} 3 \mathrm{~d}^{17 \mathrm{C}}$ to the same ligands generates an unusual two-state binding interaction. At concentrations up to the first $15.63 \mathrm{nM}$ replicate (dashed line) the binding patterns 
depict highly avid interactions suggestive of the formation of dimeric C3d ${ }^{17 \mathrm{C}}-\mathrm{CR} 2-\mathrm{Fc}$ and dimeric C3d ${ }^{17 C}-\mathrm{FH}_{19-20}$ crosslinked complexes which are not fully eluted from the surface. Thus, the subsequent injection cycles commence at a higher baseline response where the high avidity binding sites for dimeric $\mathrm{C}_{3} \mathrm{~d}^{17 \mathrm{C}}$ on $\mathrm{CR} 2-\mathrm{Fc}$ or $\mathrm{FH}_{19-20}$ remain saturated. This causes the binding mode to switch to less favourable, readily-disrupted interactions suggestive of the formation of 1:1 complexes, although some crosslinked complexes persist. Inset: baseline-adjusted sensorgrams showing the less favourable interactions at higher concentrations of dimeric $\mathrm{C} 3 \mathrm{~d}^{17 \mathrm{C}}$ which are readily eluted from the surface. Arrows depict the regeneration period. See Supplementary Figure S10 for further details and Supplementary Figure S11 for results from an additional two independent experiments. $(\mathbf{b}, \mathbf{c})$ Schematic models depicting the proposed mechanistic basis behind dimeric $\mathrm{C}^{3} \mathrm{~d}^{17 \mathrm{C}}$-mediated crosslinking of surface-associated CR2 (SCR 1-4) (b) and FH (SCR 19-20) (c). At low concentrations, C3d ${ }^{17 C}$ dimers crosslink two surface-associated CR2 (SCR 1-4) or $\mathrm{FH}_{19-20}$ molecules via highly avid interactions involving the acidic residue-lined concave face of C3d and SCRs 1 and 2 of CR2 or the convex surface and domain 19 of $\mathrm{FH}$ (top). Once a critical threshold concentration has been surpassed, the increase in dimeric $\mathrm{C} \mathrm{d}^{17 \mathrm{C}}$ molecules relative to available $\mathrm{CR} 2$ or $\mathrm{FH}_{19-20}$ binding sites outcompetes the second binding site on $\mathrm{C} \mathrm{d}^{17 \mathrm{C}}$ dimers and favours the formation of $1: 1$ complexes (middle). Unlike $\mathrm{C} 3 \mathrm{~d}^{17 \mathrm{C}}$ dimers, monomeric $\mathrm{C} 3 \mathrm{~d}^{17 \mathrm{~A}}$ lacks the ability to crosslink $\mathrm{CR} 2$ or $\mathrm{FH}_{19-20}$ and is restricted to the formation of 1:1 complexes (bottom).

In order to further investigate C3d-mediated changes in the activation state of B cells within mixed populations of cells, as would occur in vivo, flow cytometry was utilised to explore differences in the expression of CD40, CD69, CD71 and CD86 on CD19+ cells within donor human PBMC samples (see Supplementary Figures S15 and S16 for gating strategy applied). In contrast to the results gathered from isolated human B cells (Supplementary Figure 13), a clear dose-dependent relationship between $\mathrm{C} 3 \mathrm{~d}$ and $\mathrm{B}$ cell activation was observed in these experiments indicating other mononuclear cell types may be involved in B cell responsiveness, as measured by expression of the markers analysed, to free C3d (Figure 5). At concentrations $\geq 10 \mathrm{nM}$, both monomeric C3d $\mathrm{d}^{17 \mathrm{~A}}$ and chemically-linked dimeric C3 $d^{17 C}$ are able to enhance expression of the early B cell activation markers CD69 and CD86 even in the absence of BCR engagement by anti-IgM. In concert with anti$\operatorname{lgM}$ although both forms of C3d synergistically upregulate expression of these markers in a concentration-dependent manner, dimeric $\mathrm{C} 3 \mathrm{~d}^{17 \mathrm{C}}$ is found to be approximately three-fold more effective at enhancing activation than monomeric C3d ${ }^{17 A}$ (47nM vs 139 nM (CD69) and 18 nM vs 59 nM (CD86) geometric mean EC50s), perhaps through more avid interactions with CR2.

Interestingly, in contrast to CD69 and CD86, both monomeric C3d ${ }^{17 A}$ and dimeric C3 $d^{17 C}$ appear to downregulate CD40, particularly in the presence of anti-lgM, with a more pronounced reduction in expression evident in the presence of dimeric $\mathrm{C} 3 \mathrm{~d}^{17 \mathrm{C}}$. Differently still, despite achieving a substantial increase in expression in the 
bioRxiv preprint doi: https://doi.org/10.1101/2020.04.22.054700; this version posted April 23, 2020. The copyright holder for this preprint (which was not certified by peer review) is the author/funder, who has granted bioRxiv a license to display the preprint in perpetuity. It is made available under aCC-BY-NC-ND 4.0 International license.

presence of anti-IgM in the experimental time period, CD71 does not appear to be influenced by either form of C3d. Importantly, the differential marker-specific trends observed are consistent across cells gathered from all three donors analysed (data from donors 2 and 3 can be found in Supplementary Figure S17) suggesting that free $C 3 d$ (unattached to an antigen) may regulate $B$ cell activation in a selective manner and that dimeric $\mathrm{C} 3 \mathrm{~d}$ may have more potent modulatory roles than $\mathrm{C} 3 \mathrm{~d}$ monomers.

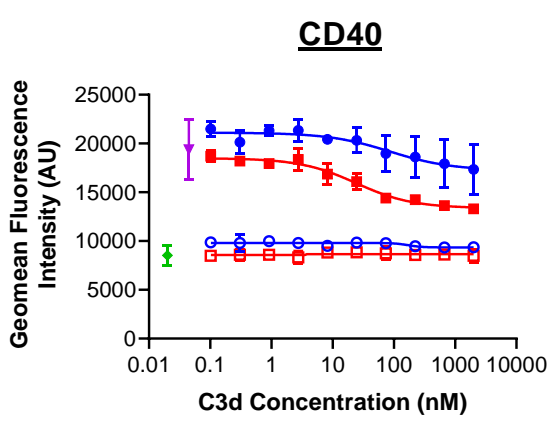

$\underline{\text { CD71 }}$

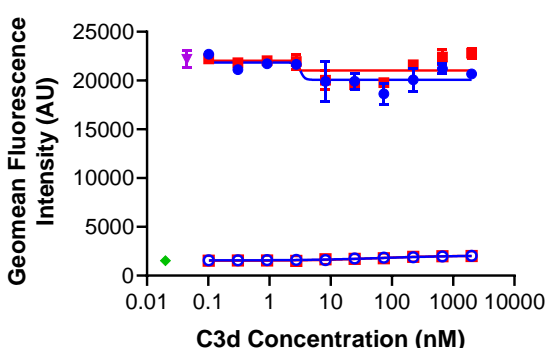

\section{$\underline{\text { CD69 }}$}

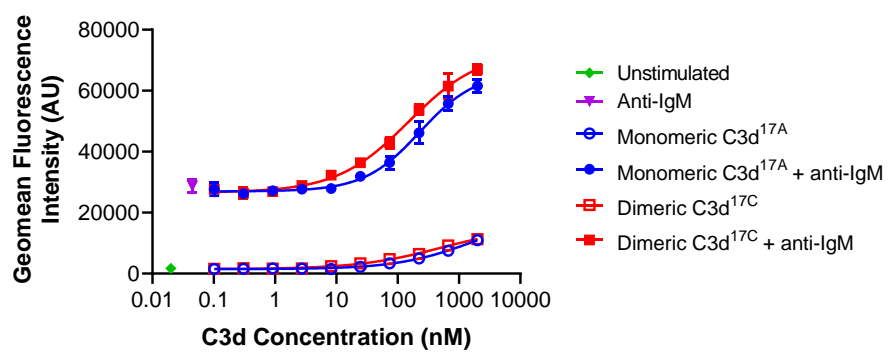

$\underline{\text { CD86 }}$

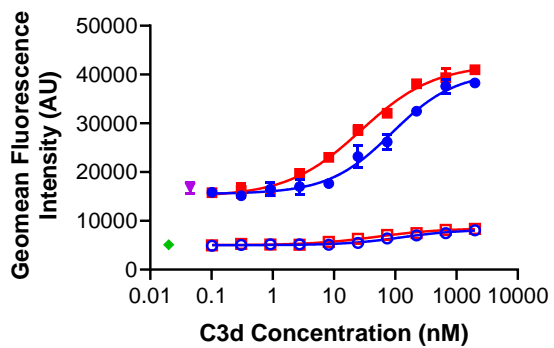

$\rightarrow$ Unstimulated

$\rightarrow$ Anti-lgM

- Monomeric C3d ${ }^{17 \mathrm{~A}}$

- Monomeric $\mathrm{C} 3 \mathrm{~d}^{17 \mathrm{~A}}+$ anti-lgM

廿 Dimeric $\mathrm{C} 3 \mathrm{~d}^{17 \mathrm{C}}$
- Dimeric C3d $\mathrm{d}^{17 \mathrm{C}}+$ anti-IgM

Figure 5. Monomeric $C 3 d^{17 A}$ and dimeric $C 3 d^{17 C}$ induce differential marker-specific changes in the activation state of PBMC B cell populations. Flow cytometric analysis of CD19+ $B$ cells stimulated with monomeric $C 3 d^{17 A}$ or dimeric $C 3 d^{17 C}$ in the presence or absence of BCR-crosslinking anti-IgM F $\left(a b^{\prime}\right)_{2}\left(10 \mu \mathrm{g} \mathrm{mL}^{-1}\right)$ reveals $\mathrm{C} 3 \mathrm{~d}$-induced changes in the expression of surface-associated $B$ cell activation markers. While no C3d-mediated changes in CD71 expression are evident, at higher concentrations $\left(\geq 3 \mathrm{nM}\right.$ ) both monomeric $\mathrm{C} 3 \mathrm{~d}^{17 \mathrm{~A}}$ and dimeric $\mathrm{C} 3 \mathrm{~d}^{17 \mathrm{C}}$ appear to downregulate CD40, with a more pronounced reduction in expression in the presence of dimeric $\mathrm{C} 3 \mathrm{~d}^{17 \mathrm{C}}$. Conversely, in the presence of anti-IgM, both monomeric $\mathrm{C} 3 \mathrm{~d}^{17 \mathrm{~A}}$ and to a greater extent dimeric $\mathrm{C} 3 \mathrm{~d}^{17 \mathrm{C}}$ synergistically upregulate CD69 and CD86 although at concentrations $\geq 10 \mathrm{nM}$ both forms of C3d are also capable of enhancing expression of these activation markers in the absence of anti-IgM. Data are of PBMC $B$ cell populations from a representative donor and displayed as mean values $(n=2) \pm$ standard deviation from the mean with curves fitted using a non-linear regression model. Results from an additional two donors can be found in Supplementary Figure S17. 


\section{Discussion}

In the past, pre-treatment of C3b with sulfhydryl-alkylating agents and routine use of a recombinant $\mathrm{C} 17 \mathrm{~A} \mathrm{C3d}$ construct has prohibited the structural and functional analysis of disulphide-linked dimers of C3 fragments that can form following activation in the fluid phase. In this study, we present the first X-ray crystal structure of a human C3d dimer where dimerisation is mediated by partial disulphide linkage of the thioester cysteine residues at position 17/1010 (C3d numbering/intact pre-pro C3 numbering) (Figure 1) in a manner that would also permit dimerisation of C3b (Supplementary Figure S2e). Importantly, this dimer retains the ability of C3d to bind SCR domains 1-2 of CR2, the $\alpha_{M}$ integrin domain of CR3 and SCR domains 19-20 of FH (Supplementary Figures S2a-d). We also find that in the presence of domain IV of the $S$. aureus immunomodulator Sbi, dimeric C3d undergoes $\mathrm{N}$ terminal 3D domain swapping, exchanging the $\mathrm{N}$-terminal $\alpha 1$ helices of the two $\mathrm{C} 3 \mathrm{~d}$ chains (Figures 2 and 3). This domain swap structurally stabilises the dimer as evidenced by the expansion in interaction surface, enhanced number of intermolecular interactions and increase in melting temperature (Supplementary

\section{Figure S4).}

Intriguingly, the secondary binding site for Sbi-IV on the convex surface of C3d revealed previously through X-ray crystallographic, NMR chemical shift perturbation $^{15}$ and SAXS analyses ${ }^{8}$, is located near the base or hinge region of the swapped $C 3 d^{17 C} \alpha 1$ helix. It is at this position between helices $\alpha 1$ and $\alpha 2$ where SbiIV helix $\alpha 1$ forms strong interactions with the thioester cysteine C17/1010 and surrounding residues S15/1008 and Q20/1013 of C3d (Supplementary Figure $\mathbf{S} 3^{15}$ ). Thus, this alternative binding of Sbi-IV to the hinge region of the $\mathrm{N}$-terminal $\alpha 1$ helix of C3d, which in our structure is occluded by tight dimer interactions, could play an important role in the Sbi-IV-mediated helix swapping observed in the present study, particularly as helix $\alpha 1$ is prone to displacement, which has been shown to occur during the conversion of $\mathrm{C} 3$ to $\mathrm{C} \mathrm{b}^{10}$. Binding of Sbi-IV could further increase the susceptibility of this specific helix in C3d to displacement such that when two C3d monomers bound by Sbi-IV on their convex surfaces in this way are brought into close proximity, the helix a1-bound Sbi-IV molecules migrate to bind the concave face of the opposing C3d molecules, a favoured higher-affinity interaction, causing a 
reciprocal exchange of the C $3 d \alpha 1$ helices followed by disulphide linkage of the thioester cysteine residues at position 17/1010 (Figure 6). Indeed, our near-UV thermal melt analyses, which suggest $\mathrm{N}$-terminal truncation (V1_D11del) abolishes the ability of Sbi-IV to displace the N-terminal a1 helical region of $\mathrm{C} 3 \mathrm{~d}$ (Supplementary Figure S5), provide support for the proposed role of Sbi-IV interactions with the convex binding site of $\mathrm{C} 3 \mathrm{~d}$ in the molecular mechanism underlying the observed helix swap.

Following the swap, the altered placement of the swapped helix $\alpha 1$ could enhance its susceptibility to further degradation and lead to the formation of C3dt, a more compact dimer, as suggested by the previously-published structure of a truncated rat dimer which lacks the exact region of C3d involved in helix swapping (M1/994 G16/1009) ${ }^{34}$. On a broader perspective, this newly-discovered N-terminal helix swap of dimeric C3d is unique as this relatively rare structural event has not been described in C3d or a complement protein previously, although 3D domain swapping has been documented in a number of disparate proteins $\mathrm{s}^{40,43}$ and various complement components such as $\mathrm{FH}$-related proteins (FHRs ${ }^{44,45}$ are known to exist in a dimeric form. To the best of our knowledge this is also the first report of a domain swap facilitated by the binding of a ligand.

In order to complement our structural studies, we next analysed the binding of a stable chemically-linked C3d ${ }^{17 C}$ dimer (Supplementary Figures S8 and S9) to CR2 (SCR1-4) and $\mathrm{FH}_{19-20}$ using SPR. Here dimeric $\mathrm{C}^{3} \mathrm{~d}^{17 \mathrm{C}}$ showed higher avidity binding to both of the interacting partners examined, and in contrast to monomeric C3d, was found to crosslink surface-associated CR2 as well as $\mathrm{FH}_{19-20}$ (Figure 4,

Supplementary Figure $\mathbf{S} 10$ and $\mathbf{S 1 1}$ ). This crosslinking of CR2 by disulphide-linked $\mathrm{C} 3 \mathrm{~d}^{17 \mathrm{C}}$ dimers cannot be explained by the formation of higher order aggregates of dimeric $\mathrm{C}^{1} \mathrm{~d}^{17 \mathrm{C}}$ (Supplementary Figures S9c and S9d) or FH $19-20$ (Supplementary Figure S12) and is a finding that has not been observed previously but could indicate a potential physiologically-relevant role of these dimers. Future investigations will elucidate whether dimeric $\mathrm{C} 3 \mathrm{~d}^{17 \mathrm{C}}$ can crosslink its other receptor, CR3, or a combination of CR2 and CR3, as suggested by our structural superpositions (Supplementary Figures S2b and S2c). 

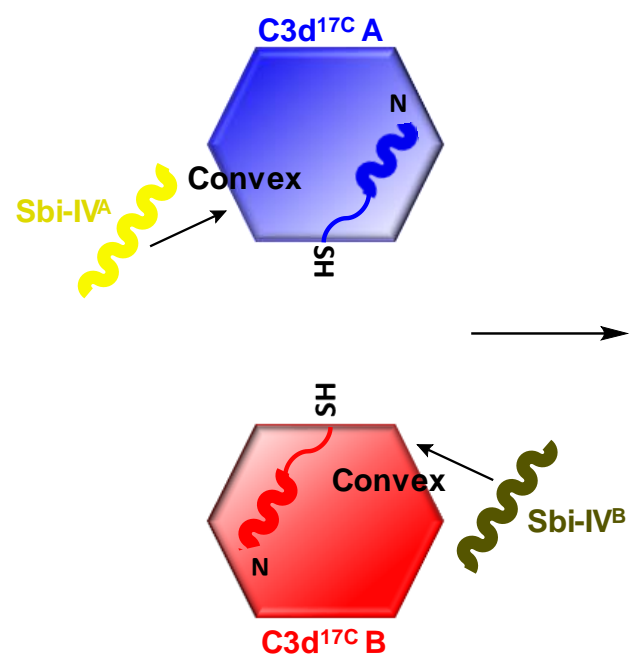
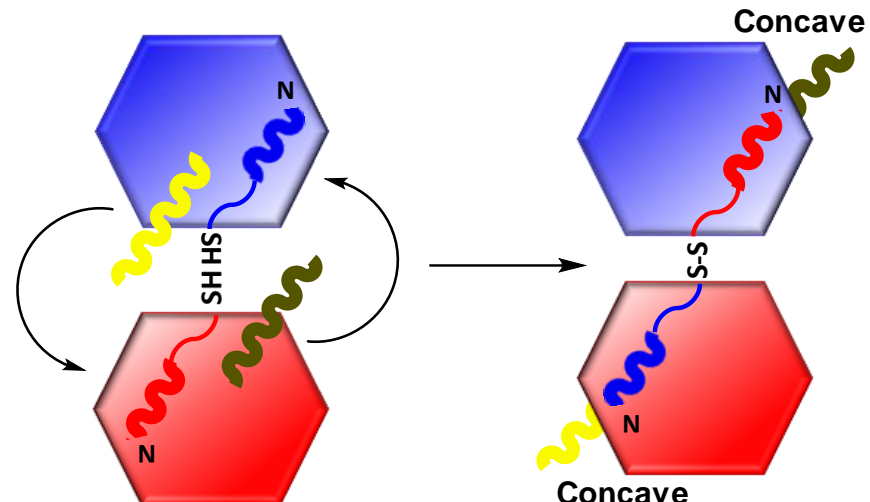

Concave

Figure 6. Schematic model depicting the proposed mechanistic basis behind Sbi-IV-induced Nterminal helix swapping of dimeric C3d ${ }^{17 C}$. Left: in the fluid phase, Sbi-IVA helix $\alpha 1$ binds to the $\mathrm{N}$ terminal helix $\alpha 1$ and its adjoining loop on the convex thioester-containing face of $C 3 d^{17 C}$ monomer $A$ (a short-distance low-affinity interaction) and similarly Sbi-IV ${ }^{\mathrm{B}}$ binds the convex face of $\mathrm{C} \mathrm{d}^{17 \mathrm{C}} \mathrm{B}$. Middle and right: when these two Sbi-IV-bound $\mathrm{C}^{1} \mathrm{~d}^{17 \mathrm{C}}$ monomers come into close proximity, Sbi-IVA helix $\alpha 2$ is attracted to and binds the concave face of $C 3 d^{17 C} B$ (a more favourable higher affinity interaction), pulling $C 3 d^{17 C} A$ helix $\alpha 1$ with it. A similar change in binding mode occurs with Sbi-IVB binding the concave face of $C 3 d^{17 C} A$ resulting in a reciprocal exchange of the $\mathrm{N}$-terminal $\alpha 1$ helices of the two $\mathrm{C} 3 \mathrm{~d}^{17 \mathrm{C}}$ monomers. The switch in Sbi-IV binding mode from the convex to the concave surface of C3d releases the thioester domain allowing the formation of a disulphide bond between the thioester cysteines of the two $\mathrm{C} 3 \mathrm{~d}^{17 \mathrm{C}}$ monomers and hence the formation of a helix-swapped C3d dimer. For the purposes of simplicity only the N-terminal helix of $\mathrm{C} 3 \mathrm{~d}^{17 \mathrm{C}}$ and one Sbi-IV helix are shown.

Finally, we investigated the effects of dimeric compared to monomeric C3d on the activation state of primary human and mouse $\mathrm{B}$ cells using flow cytometry and $\mathrm{Ca}^{2+}$ influx experiments. When assayed in isolation, B cells purified from human PBMCs appeared to be unresponsive to both forms of free C3d (Supplementary Figure S13). However, both monomeric $\mathrm{C} 3 \mathrm{~d}^{17 \mathrm{~A}}$, and to a greater extent dimeric $\mathrm{C} 3 \mathrm{~d}^{17 \mathrm{C}}$, inhibited $\mathrm{BCR} / \mathrm{CR} 2-$-mediated $\mathrm{Ca}^{2+}$ influx in $\mathrm{B}^{2} 20^{+}$murine splenocytes when added prior to stimulation with a BCR/CR2-crosslinking complex (Supplementary Figure S14). Further to previous reports using biotinylated C3dg (with a C17A mutation) in the presence of streptavidin ${ }^{46}$, these results suggest that pre-ligation of CR2 by naturally-occurring fluid phase $\mathrm{C} 3 \mathrm{~d}(\mathrm{~g})$ dimers could inhibit $\mathrm{BCR} / \mathrm{CR} 2$ crosslinkingmediated $\mathrm{Ca}^{2+}$ responses in $\mathrm{B}$ cells by sequestering the CR2/CD19/CD81 receptor complex from the BCR with higher avidity than C3d monomers. 
Both dimeric and monomeric C3d were also found to induce changes in the expression of B cell activation markers on human CD19+ cells within PBMC samples (Figure 5, Supplementary Figure S17). Specifically, in the presence of anti-IgM, both monomeric C3 $d^{17 A}$ and to a three-fold greater extent dimeric $C 3 d^{17 C}$, synergistically upregulated CD69 and CD86 which is consistent with previous reports showing independent ligation of CR2 and the BCR (i.e. without crosslinking) by simultaneous stimulation with biotinylated-C3dg/streptavidin complexes and anti-IgM can augment $\mathrm{B}$ cell activation ${ }^{47}$. Our results, however, additionally show that dimeric C3d ${ }^{17 C}$ is more efficient at augmenting CR2/BCR-dependent activation and that BCR engagement may not be necessary for upregulation of certain activation makers as at higher concentrations both forms of C3d were also capable of enhancing expression of the early activation markers CD69 and CD86 in the absence of anti$\lg \mathrm{M}$.

In contrast to CD69 and CD86, both monomeric and dimeric C3d appeared to downregulate CD40, with a more pronounced reduction in expression in the presence of dimeric $\mathrm{C} 3 \mathrm{~d}^{17 C}$. CD40 is involved in the regulation of several $\mathrm{B}$ cell processes including germinal centre reactions ${ }^{48}$, isotype switching ${ }^{49}$ and somatic hypermutation ${ }^{50}$ and has also been shown to prevent $B$ cells from becoming anergic $^{51}$. In line with these roles, downregulation of CD40 was shown to be a beneficial outcome of Rituximab treatment of systemic lupus erythematosus (SLE) patients $^{52}$ and CD40/CD40L levels have been linked to anti-DNA autoantibody titres in lupus patients ${ }^{53}$ and mouse models ${ }^{54}$. Although further investigations are required to explain the C3d-mediated downregulation of CD40 expression on B cells observed in our study, it is possible that C3d stimulation of CR2 or CR3 expressed on other PBMC cell types (e.g. T cells ${ }^{55-58}$ and natural killer cells ${ }^{59}$ ) induces the production of higher levels of soluble CD40L that drive internalisation of CD40 or prevent efficient staining by occluding the receptor. Alternatively, the known binding of CD40L to $\mathrm{CR}^{60}$ could be outcompeted by CR3 interactions with C3d, particularly in its dimeric form, elevating the levels of soluble CD40L available for binding CD40. Further experiments investigating the effects of free monomeric and dimeric C3d on IgG titre and hence B-cell differentiation or antibody class switching following activation of PBMCs with T cell supernatants or co-culture with IL-2 or CD40Lproducing feeder cells will help to understand this process further. 
On the whole, our cell experiments not only suggest free fluid-phase C3d(g) (unattached to a surface) may regulate $B$ cell activation in a selective manner but also that there are clear functional differences between monomeric and dimeric C3d with the latter being a more potent modulator of the activation state of $B$ cells as a consequence of high avidity receptor interactions or through receptor crosslinking. In addition, they indicate other PBMC cell types play an important role in the responsiveness of $B$ cells, in terms of the activation markers analysed, to C3d, perhaps through the provision of sensitising or synergising co-stimulatory molecules or via CR2-CR2 or CR2-CR3 crosslinking between cells.

Together with the fact that C3d inhibited BCR/CR2-mediated $\mathrm{Ca}^{2+}$ influx prior to stimulation with a BCR/CR2-crosslinking complex, the C3d-induced downregulation of CD40 expression could also signify fluid-phase C3d(g), particularly in its dimeric form, may alter the activation of B cells and direct them towards an anergic state. This would be logical in terms of helping to limit the involvement of complement in the generation of humoral immune responses in the absence of a threat and is consistent with reports of CR2 ligation being involved in the anergy of autoreactive $B$ cells $47,61,62$. Thus, C3d(g) dimers could have implications for the development of novel therapies for autoimmune diseases through their effects on CD40/CD40L interactions which along with B cell anergy, are also critical for the maintenance of peripheral self-tolerance by immature dendritic cells $(D C s)^{63}$, known to express $\mathrm{CR}^{64,65}$. By extension, these newly-uncovered functions of C3d could also offer a possible explanation as to why humoral immune responses are inhibited, rather than enhanced, by certain vaccine constructs composed of antigens linked to linear repeats of C3d placed in close proximity to each other ${ }^{47,66}$.

If free $\mathrm{C} 3 \mathrm{~d}(\mathrm{~g})$, more notably in its dimeric form, does in fact play a role in anergising or inducing a state of tolerance in B cells, then in addition to sequestering CR2 away from $S$. aureus surfaces and antigens, the consumptive cleavage of $\mathrm{C} 3$ in the fluid phase followed by stabilisation of disulphide-linked C3d dimers through domain swapping mediated by Sbi could promote B cell anergy, as well more widespread tolerance through possible effects on T cells and DCs, and thereby further facilitate evasion of the immune system by $S$. aureus. Future investigations could elucidate whether these interactions between Sbi and C3d and their resultant functional 
consequences are involved in the known association between $S$. aureus infections and autoimmune diseases ${ }^{67}$. In a wider context, it would also be interesting to explore possible connections between the levels of $\mathrm{C} 3 \mathrm{~d}(\mathrm{~g})$ dimers, their distribution in the body and pathological conditions associated with uncontrolled C3 activation, such as C3 glomerulopathy, as we surmise local upregulation of fluid phase C3d(g) concentrations is likely to enhance $\mathrm{C} 3 \mathrm{~d}(\mathrm{~g})$ dimerisation.

In summary, in this study we present the first structures of fluid-phase disulphidelinked human C3d dimers and through accompanying functional analyses show that these dimers have physiologically-relevant roles in crosslinking CR2 and selectively modulating B cell activation, possibly to trigger tolerogenic pathways, which could have implications for autoimmune diseases. In addition, our new discovery that Sbi domain IV can induce structurally-stabilising domain swapping of dimeric C3d, a unique example in the field of structural biology of the complement system, reveals another dimension in the complex relationship between $S$. aureus and the immune system and could signify a novel staphylococcal B cell subversion strategy. Overall, our findings shed light on a fundamental aspect of complement biology that is often overlooked and have the potential to inform the design of novel therapeutics for autoimmune diseases in the future. 


\section{Materials and Methods}

\section{Expression and purification of recombinant proteins}

The DNA sequence of human C3d (residues 1-310) comprised of C3 residues 9961303 (pre-pro C3 numbering) with a Cys to Ala mutation at position 17(C3d)/1010 (pre-pro C3) (C3d $\left.{ }^{17 A}\right)$ was previously cloned into the pET15b expression plasmid ${ }^{12}$. To reproduce the wild-type sequence, the Ala at position 17 of the $\mathrm{C} 3 \mathrm{~d}^{17 \mathrm{~A}}$ construct was reverted back to a Cys $\left(\mathrm{C} \mathrm{d}^{17 \mathrm{C}}\right)$ using site-directed mutagenesis. Both $\mathrm{C} 3 \mathrm{~d}$ constructs were expressed in the Escherichia coli BL21(DE3) (Sigma Aldrich) or Shuffle T7 (NEB) cell lines and purified using cation exchange followed by size exclusion chromatography.

The DNA sequence of the Sbi construct composed of domain IV (150-266 of fulllength Sbi) bearing an N-terminal $6 x$ His-tag was previously cloned into the PQE30 plasmid ${ }^{15}$ while the DNA sequence of a truncated Sbi-IV construct lacking 11 residues located at the N-terminus of helix a1 (198-208 of full-length Sbi) (V1_D11del) was produced using PCR with designed primers and cloned into the pET28a plasmid. Both Sbi constructs were expressed in E. coli BL21(DE3) cells and purified using nickel-affinity and size exclusion chromatography.

The human $\mathrm{CR}$ 2(SCR1-4)-Fc and $\mathrm{FH}_{19-20}$ constructs used in surface plasmon resonance experiments were expressed in Chinese hamster ovary $(\mathrm{CHO})$ cells or Pichia pastoris respectively and purified as described previously (CR2(SCR1-4)-Fc: 7; $\mathrm{FH}_{19-20:}{ }^{68}$ ). The monomeric state of $\mathrm{FH}_{19-20}$ was confirmed using analytical ultracentrifugation (Supplementary Figure S12).

\section{Crystallisation, data collection and structure determination of dimeric $\mathrm{C} \mathrm{d}^{17 \mathrm{C}}$ and a C $3 \mathbf{d}^{17 \mathrm{C}}$ dimer-Sbi-IV complex}

Crystallisation was performed at $18^{\circ} \mathrm{C}$ using the hanging drop vapour diffusion method. For the dimeric C $3 d^{17 \mathrm{C}}$ structure, a $15 \mathrm{mg} \mathrm{mL}^{-1}(432 \mu \mathrm{M}) \mathrm{C} 3 \mathrm{~d}^{17 \mathrm{C}}$ solution was subjected to a grid screen containing $100 \mathrm{mM}$ Tris pH 8, 50-300 mM NaCl and 16-26\% PEG 4000. Crystals appeared in the condition containing $100 \mathrm{mM}$ Tris $\mathrm{pH}$ 8, $200 \mathrm{mM} \mathrm{NaCl}, 24 \%$ PEG 4000 . For the C3d ${ }^{17 \mathrm{C}}$ dimer-Sbi-IV complex structure, needle-like co-crystals at a 1:1 molar $(288 \mu \mathrm{M})$ ratio of Sbi-IV $\left(2.66 \mathrm{mg} \mathrm{mL}^{-1}\right)$ and $\mathrm{C} 3 \mathrm{~d}^{17 \mathrm{C}}\left(10 \mathrm{mg} \mathrm{mL}^{-1}\right)$ appeared in the condition containing $0.2 \mathrm{M}$ Sodium citrate 
tribasic dihydrate, 20\% PEG 3350 (PACT premier condition E11, Molecular Dimensions) (measured $\mathrm{pH}: 8.07)$.

Crystals were mounted on loops, flash-frozen in liquid nitrogen and X-ray diffraction data collected on the 104 beamline at the Diamond Light Source synchrotron (Oxfordshire, UK) (See Supplementary Table S1 for data collection statistics). Integration of Dectris PILATUS 6M pixel detector diffraction images and data reduction were performed using Xia2-DIALS and AIMLESS respectively. The automated BALBES pipeline and COOT were used for molecular replacement and model building. Refinement was carried out in REFMAC and Phenix (refinement statistics can be found in Supplementary Table S2) and UCSF Chimera was used for superpositioning and generation of images. Bond numbers and buried surface area were calculated with PDBePISA. Both structures have been submitted to the PDB with the following submission codes: 6RMT (C3 $d^{17 C}$ dimer) and 6RMU (C3 ${ }^{17 C}$ dimer-Sbi-IV complex).

\section{Circular dichroism (CD) spectroscopy}

For tertiary structure thermal melt analyses, buffer-corrected CD measurements of $87.5 \mu \mathrm{M} \mathrm{C} 3 \mathrm{~d}^{17 \mathrm{C}}$ or $\mathrm{C} 3 \mathrm{~d}^{17 \mathrm{~A}}$ alone or in the presence of an equimolar concentration of wild-type Sbi-IV or an Sbi-IV truncation mutant (V1_D11del) in $10 \mathrm{mM}$ phosphate pH 7.4 were acquired at wavelengths between 250 and $320 \mathrm{~nm}$ in $1 \mathrm{~nm}$ increments. 50 $\mu \mathrm{g} \mathrm{mL}^{-1} \mathrm{C} 3 \mathrm{~d}^{17 \mathrm{C}}$ or $\mathrm{C} 3 \mathrm{~d}^{17 \mathrm{~A}}$ and wavelengths between 190 and $280 \mathrm{~nm}$ were used for secondary structure analyses. All measurements were obtained on a Chirascan spectrometer (Applied Photophysics) with a bandwidth of $2 \mathrm{~nm}$ and 2 second time per point at temperatures ranging from $5^{\circ} \mathrm{C}$ to $85^{\circ} \mathrm{C}$ in $5^{\circ} \mathrm{C}$ increments followed by a final reading at $20^{\circ} \mathrm{C}$. Millidegree values were converted to units of mean residue ellipticity and deconvolution of secondary structural data was performed using DichroWeb. Melting temperature values were estimated using sigmoidal fits of thermal denaturation curves at different wavelengths performed using the Boltzmann function in GraphPad Prism (version 8.4.1). See Supplementary Figures S4 and S5 for near-UV thermal melt analysis of $C 3 d^{17 C}$ and $C 3 d^{17 A}$ and sigmoidal fits of thermal denaturation curves used for Tm calculations and Supplementary Figure S6 for farUV thermal melt studies of $C 3 d^{17 C}$ and $C 3 d^{17 A}$. 


\section{Synthesis and characterisation of N,N'-(propane-1,3-diyl) bis(2- bromoacetamide) linker}<smiles>O=C(CBr)NCCCNC(=O)CBr</smiles>

A solution of $\mathrm{K}_{2} \mathrm{CO}_{3}(5.92 \mathrm{~g}, 42.8 \mathrm{mmol})$ in water $(21 \mathrm{~mL})$ was added to a solution of 1,3-diaminopropane $(1.06 \mathrm{~g}, 14.3 \mathrm{mmol})$ in chloroform $(35 \mathrm{~mL})$ at $5^{\circ} \mathrm{C}$ with stirring. $\mathrm{A}$ solution of bromoacetyl bromide ( $8.65 \mathrm{~g}, 42.8 \mathrm{mmol}$ ) in anhydrous chloroform (15 $\mathrm{mL}$ ) was then added dropwise to the mixture and the reaction was left stirring at room temperature for 18 hours. The resultant precipitate was filtered, washed with water $(6 \times 10 \mathrm{~mL})$, and dried under vacuum to yield $N, N^{\prime}$-(propane-1,3-diyl)bis(2bromoacetamide) as a white solid (2.45 g, 55\%). Subsequent characterisation of the linker was performed using ${ }^{1} \mathrm{H}-\mathrm{NMR}$ (Supplementary Figure S7a) and ${ }^{13} \mathrm{C}-\mathrm{NMR}$ (Supplementary Figure S7b). High resolution electrospray ionisation time-of-flight mass spectrometry $\mathrm{m} / \mathrm{z}:[\mathrm{M}+\mathrm{Na}]^{+}$calculated for $\mathrm{C}_{7} \mathrm{H}_{12} \mathrm{Br}_{2} \mathrm{~N}_{2} \mathrm{O}_{2} \mathrm{Na}=338.9143 \mathrm{Da}$, 338.9143 Da was observed.

\section{Production, purification and characterisation of chemically-linked C3d dimers}

For the generation of chemically-linked $C 3 d^{17 C}$ dimers, small-scale trials were performed involving combination of $\mathrm{C} 3 \mathrm{~d}^{17 \mathrm{C}}$ with the $N^{\prime} N^{\prime}$-(propane-1,3-diyl)bis(2bromoacetamide) linker in 0.1 M Tris, $0.15 \mathrm{M} \mathrm{NaCl}, 5 \mathrm{mM}$ EDTA pH 7.5 at 0.55, 0.75 or 1.0 molar equivalences. Following overnight incubation at room temperature $\left(21^{\circ} \mathrm{C}\right)$, linker-mediated $\mathrm{C} 3 \mathrm{~d}^{17 \mathrm{C}}$ dimerisation was confirmed using reducing SDSPAGE and electrospray time-of-flight mass spectrometry (Supplementary Figure

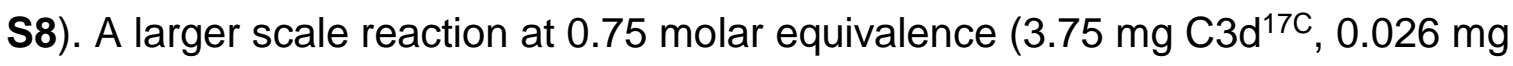
linker) was subsequently carried out as described above and subjected to size exclusion chromatography to separate the chemically-linked dimeric $C 3 d^{17 C}$ from monomeric C3 $d^{17 C}$ (Supplementary Figures S9a and S9b). Particle size analysis yielded a single species (Supplementary Figure S9c), analytical ultracentrifugation confirmed the dimeric state of the chemically-linked C3d ${ }^{17 C}$ (Supplementary Figure S9d) and both biophysical techniques showed a lack of aggregate formation. Chemically-linked dimeric C $3 d^{17 C}$ was subsequently digested with trypsin (1:50 ratio) at $37^{\circ} \mathrm{C}$ over a time course (Supplementary Figure S9e). The digestion reaction 
was stopped by addition of a trypsin inhibitor (1:2 ratio). Electrospray ionization timeof-flight mass spectrometry of the trypsin-digested dimeric C $3 d^{17 C}$ fragments followed by analysis using the Masshunter Qualitative Analysis and BioConfirm (Agilent) software packages was used to confirm chemical linkage at position 17C of C3d (Supplementary Table S3) and the presence of an intact internal disulphide bond (Supplementary Table S4).

\section{Surface plasmon resonance}

All surface plasmon resonance experiments were performed on a Biacore S200 sensor (GE Healthcare) at $25^{\circ} \mathrm{C}$ with HBST (10 mM HEPES, $150 \mathrm{mM} \mathrm{NaCl}, 0.005 \%$ Tween-20, $\mathrm{pH}$ 7.4) used as the running buffer. $\mathrm{CR} 2-\mathrm{Fc}$ and $\mathrm{FH}_{19-20}$ were prepared in $10 \mathrm{mM}$ sodium acetate $\mathrm{pH} 5$ and immobilised at $300 \mathrm{RU}$ (CR2-Fc: $20 \mu \mathrm{M}, \mathrm{FH}_{19-20}$ : $240 \mu \mathrm{M}$ ) to different flow cells of CM5 chips (GE Healthcare) using standard amine coupling involving preparation of the dextran matrix with $100 \mathrm{mM} \mathrm{N}$ hydroxysuccinimide (NHS) and $40 \mathrm{mM}$ 1-ethyl-3-(dimethylaminopropyl) carbodiimide (EDC) followed by quenching with $1 \mathrm{M}$ ethanolamine- $\mathrm{HCl} \mathrm{pH}$ 8.5. Monomeric $\mathrm{C} 3 \mathrm{~d}^{17 \mathrm{~A}}$ and chemically-linked dimeric $\mathrm{C} 3 \mathrm{~d}^{17 \mathrm{C}}$ used as analytes were prepared to a fixed concentration, serially diluted in HBST and injected in duplicate. $10 \mathrm{mM}$ sodium acetate, $1 \mathrm{M} \mathrm{NaCl} \mathrm{pH} 4$ was used as the regeneration buffer but could not regenerate the chip surface of the highly avid interactions between dimeric C3d ${ }^{17 C}$ and $\mathrm{CR} 2-\mathrm{Fc} / \mathrm{FH}_{19-20}$. Data were analysed using the Biacore S200 Evaluation Software 1.0. Responses from blank reference flow cells were subtracted from ligand-immobilised flow cells and all data were double-referenced (buffer inject subtracted).

\section{Flow cytometric analysis of $B$ cell activation}

Frozen human peripheral blood mononuclear cells (PBMCs) from blood donors were thawed and diluted into cold RPMI 1640 medium (Gibco) supplemented with 10\% (v/v) foetal bovine serum, 1\% (v/v) penicillin-streptomycin (Sigma Aldrich) and 1\% (v/v) GlutaMAX (Gibco). For experiments on isolated B cells, B cells were purified from PBMCs by negative selection using the Miltenyi Biotec Human B Cell Isolation Kit II as per the manufacturer's instructions. Following centrifugation, cells were 
counted, assessed for viability, which typically exceeded $90 \%$ for PBMCs and $80 \%$ for $\mathrm{B}$ cells, and re-suspended to the desired density in ambient medium.

PBMCs or B cells were then seeded onto sterile V-bottom plates at a density of 150,000 or 40,000 cells/well respectively and allowed to recover at $37^{\circ} \mathrm{C}$ with $5 \%$ $\mathrm{CO}_{2}$ for $1 \mathrm{~h}$. Monomeric $\mathrm{C} 3 \mathrm{~d}^{17 \mathrm{~A}}$ or chemically-linked dimeric C3 $\mathrm{d}^{17 \mathrm{C}}$ were serially diluted in media and added to the cells in duplicate to give final concentrations ranging from $2 \mu \mathrm{M}$ to $0.1 \mathrm{nM}$ (based on the molecular weight of monomeric C3 $\mathrm{d}^{17 \mathrm{~A}}$ for both constructs in order to control for the number of binding sites). Following a 30 min incubation period with the C3d constructs, additions of either goat $F(a b$ ')2 antihuman IgM LE/AF (Southern Biotech) at a final concentration of $10 \mu \mathrm{g} \mathrm{mL}^{-1}$ or media were made and the cells incubated for a further $18 \mathrm{~h}$ at $37^{\circ} \mathrm{C}$ with $5 \% \mathrm{CO}_{2}$.

After a period of cooling on ice, the cells were stained for $1 \mathrm{~h}$ with the LIVE/DEAD ${ }^{\text {TM }}$ fixable near-infrared dead cell stain (1:1000 dilution, Invitrogen) along with the following labelled antibodies diluted in an ice-cold staining buffer (PBS supplemented with $1 \%$ BSA, 2mM EDTA and $0.05 \% \mathrm{NaN}_{3}$ ): PerCP-Cy ${ }^{\text {TM }} 5.5$ mouse anti-human CD19 (1:40 dilution, Clone HIB19, BD Pharmingen) (for PBMC samples only), FITC mouse anti-human CD40 (1:20 dilution, Clone 5C3, BD Pharmingen), Brilliant Violet 421 ${ }^{\mathrm{TM}}$ mouse anti-human CD69 (1:40 dilution, Clone FN50, BioLegend), PE mouse anti-human CD71 (1:20 dilution, Clone M-A712, BD Pharmingen) and APC mouse anti-human CD86 (1:20 dilution, Clone 2331, BD Pharmingen). The cells were subsequently washed and analysed on an Intellicyt $\AA$ iQue Screener PLUS flow cytometer. The gating strategy applied for live, singlet CD19+ B cells and activation markers can be found in Supplementary Figures S15 and S16, respectively. Antibody capture beads were used for compensation. Data were expressed as mean values from at least 2 replicates \pm standard deviation from the mean and depicted as scatter plots with curves fitted using a four parameter variable slope non-linear regression model in GraphPad Prism (version 8.4.1).

\section{$\mathrm{Ca}^{2+}$ influx experiments}

Intracellular $\mathrm{Ca}^{2+}$ measurements using flow cytometry were performed as described previously $46,69,70$. Briefly, isolated C57BL/6 mouse splenocytes maintained at $37^{\circ} \mathrm{C}$ were Indo 1-AM loaded, stained with a rat anti-mouse CD45R/B220-APC antibody 
(Clone RA3-6B2, BD Pharmingen) and analysed on a BD LSR II flow cytometer (BD Biosciences) at RT. 4 or $10 \mu \mathrm{g}$ of monomeric $\mathrm{C} 3 \mathrm{~d}^{17 \mathrm{~A}}$ or chemically-linked dimeric C3 ${ }^{17 C}$ were added to the cells 30 s after data acquisition. After 90 s, cells were stimulated with a suboptimal concentration of pre-mixed complexes composed of $0.056 \mu \mathrm{g} \mathrm{mL}^{-1}$ biotinylated $\mathrm{F}(\mathrm{ab}$ ')2 goat anti-mouse IgM ( $\mu$-chain specific) (Jackson ImmunoResearch), $\sim 3 \mu \mathrm{g} \mathrm{mL}^{-1} \mathrm{C} 3 \mathrm{dg}$-biotin (produced in house) and $\sim 1.3 \mu \mathrm{g} \mathrm{mL}^{-1}$ streptavidin (algM-b/C3dg-b/ST). Experiments were run for $10 \mathrm{~min}$ and intracellular $\mathrm{Ca}^{2+}$ influx of gated $\mathrm{B} 220^{+}$cells was analysed using the FlowJo® software (FlowJo LLC, BD).

\section{Data Availability}

The datasets generated and analysed during the current study are available from the corresponding authors on request. 


\section{References}

1. Carter, R. \& Fearon, D. Polymeric C3dg Primes Human B Lymphocytes for Proliferation Induced By Anti-IgM. J. Immunol. 143, 1755-1760 (1989).

2. Dempsey, P., Allison, M., Akkaraju, S., Goodnow, C. \& Fearon, D. C3d of complement as a molecular adjuvant: Bridging innate and acquired immunity. Science 271, 348-350, doi:10.1126/science.271.5247.348 (1996).

3. Ross, T., Xu, Y., Bright, R. \& Robinson, H. C3d enhancement of antibodies to hemagglutinin accelerates protection against influenza virus challenge. Nat. Immunol. 1, 127-131, doi:10.1038/77802 (2000).

4. Green, T. et al. C3d enhancement of neutralizing, antibodies to measles hemagglutinin. Vaccine 20, 242-248, doi:10.1016/S0264-410X(01)00266-3 (2001).

5. Henson, S., Smith, D., Boackle, S., Holers, V. \& Karp, D. Generation of recombinant human C3dg tetramers for the analysis of CD21 binding and function. J. Immunol. Methods 258, 97-109, doi:10.1016/S00221759(01)00471-9 (2001).

6. Green, T. D., Montefiori, D. C. \& Ross, T. M. Enhancement of antibodies to the human immunodeficiency virus type 1 envelope by using the molecular adjuvant C3d. J. Virol. 77, 2046-2055, doi:10.1128/Jvi.77.3.2046-2055.2003 (2003).

7. He, Y. et al. A novel C3d-containing oligomeric vaccine proVides insight into the viability of testing human C3d-based vaccines in mice. Immunobiology 223, 125-134, doi:10.1016/j.imbio.2017.10.002 (2017).

8. Yang, Y. et al. Utilization of Staphylococcal Immune Evasion Protein Sbi as a Novel Vaccine Adjuvant. Front. Immunol. 9, doi:10.3389/fimmu.2018.03139 (2019).

9. Janssen, B. et al. Structures of complement component C3 provide insights into the function and evolution of immunity. Nature 437, 505-511, doi:10.1038/nature04005 (2005).

10. Janssen, B., Christodoulidou, A., McCarthy, A., Lambris, J. \& Gros, P. Structure of $\mathrm{C} 3 \mathrm{~b}$ reveals conformational changes that underlie complement activity.

Nature 444, 213-216, doi:10.1038/nature05172 (2006).

11. Xue, X. et al. Regulator-dependent mechanisms of C3b processing by factor I allow differentiation of immune responses. Nat. Struct. Mol. Biol. 24, 643-651, doi:10.1038/nsmb.3427 (2017).

12. Nagar, B., Jones, R., Diefenbach, R., Isenman, D. \& Rini, J. X-ray crystal structure of C3d: A C3 fragment and ligand for complement receptor 2. Science 280, 1277-1281, doi:10.1126/science.280.5367.1277 (1998).

13. van den Elsen, J. \& Isenman, D. A Crystal Structure of the Complex Between Human Complement Receptor 2 and Its Ligand C3d. Science 332, 608-611, doi:10.1126/science.1201954 (2011).

14. Vorup-Jensen, T. \& Jensen, R. Structural Immunology of Complement Receptors 3 and 4. Front. Immunol. 9, doi:10.3389/fimmu.2018.02716 (2018).

15. Clark, E. et al. A structural basis for Staphylococcal complement subversion: Xray structure of the complement-binding domain of Staphylococcus aureus protein Sbi in complex with ligand C3d. Mol. Immunol. 48, 452-462, doi:10.1016/j.molimm.2010.09.017 (2011). 
16. Hammel, M. et al. A structural basis for complement inhibition by Staphylococcus aureus. Nat. Immunol. 8, 430-437, doi:10.1038/ni1450 (2007).

17. Ricklin, D., Ricklin-Lichtsteiner, S. K., Markiewski, M. M., Geisbrecht, B. V. \& Lambris, J. D. Cutting Edge: Members of the Staphylococcus aureus Extracellular Fibrinogen-Binding Protein Family Inhibit the Interaction of C3d with Complement Receptor 2. J. Immunol. 181, 7463-7467, doi:10.4049/jimmunol.181.11.7463 (2008).

18. Hammel, M. et al. Characterization of Ehp, a secreted complement inhibitory protein from Staphylococcus aureus. J. Biol. Chem. 282, 30051-30061, doi:10.1074/jbc.M704247200 (2007).

19. Amdahl, H. et al. Staphylococcal Ecb Protein and Host Complement Regulator Factor $\mathrm{H}$ Enhance Functions of Each Other in Bacterial Immune Evasion. J. Immunol. 191, 1775-1784, doi:10.4049/jimmunol.1300638 (2013).

20. Kajander, T. et al. Dual interaction of factor $\mathrm{H}$ with $\mathrm{C} 3 \mathrm{~d}$ and glycosaminoglycans in host-nonhost discrimination by complement. Proc. Natl. Acad. Sci. USA 108, 2897-2902, doi:10.1073/pnas.1017087108 (2011).

21. Morgan, $\mathrm{H}$. et al. Structural basis for engagement by complement factor $\mathrm{H}$ of C3b on a self surface. Nat. Struct. Mol. Biol. 18, 463-470, doi:10.1038/nsmb.2018 (2011).

22. Law, S. K. A. \& Dodds, A. W. The internal thioester and the covalent binding properties of the complement proteins C3 and C4. Protein Sci. 6, 263-274, doi:10.1002/pro.5560060201 (1997).

23. Bexborn, F., Andersson, P., Chen, H., Nilsson, B. \& Ekdahl, K. The tick-over theory revisited: Formation and regulation of the soluble alternative complement $\mathrm{C} 3$ convertase $\left(\mathrm{C} 3\left(\mathrm{H}_{2} \mathrm{O}\right) \mathrm{Bb}\right)$. Mol. Immunol. 45, 2370-2379, doi:10.1016/j.molimm.2007.11.003 (2008).

24. Perkins, S. J. \& Sim, R. B. Molecular Modeling of Human-Complement Component-C3 and Its Fragments by Solution Scattering. Eur. J. Biochem. 157, 155-168, doi:10.1111/j.1432-1033.1986.tb09652.x (1986).

25. Rodriguez, E., Nan, R., Li, K., Gor, J. \& Perkins, S. A Revised Mechanism for the Activation of Complement C3 to C3b - A Molecular Explanation of a Disease-Associated Polymorphism. J. Biol. Chem. 290, 2334-2350, doi:10.1074/jbc.M114.605691 (2015).

26. Arnaout, M., Melamed, J., Tack, B. \& Colten, H. Characterization of the Human Complement (C3b) Receptor with a Fluid Phase C3b Dimer. J. Immunol. 127, 1348-1354 (1981).

27. Melamed, J., Arnaout, M. \& Colten, H. Complement (C3b) Interaction with the Human Granulocyte Receptor - Correlation of Binding of Fluid-Phase Radiolabeled Ligand with Histaminase Release. J. Immunol. 128, 2313-2318 (1982).

28. Kinoshita, T. et al. C5 Convertase of the Alternative Complement Pathway Covalent Linkage Between 2 C3b Molecules within the Trimolecular Complex Enzyme. J. Immunol. 141, 3895-3901 (1988).

29. Hong, K. et al. Reconstitution of C5 Convertase of the Alternative Complement Pathway with Isolated C3b Dimer and Factors B and D. J. Immunol. 146, 18681873 (1991).

30. Jelezarova, E., Luginbuehl, A. \& Lutz, H. C3b2-IgG complexes retain dimeric C3 fragments at all levels of inactivation. J. Biol. Chem. 278, 51806-51812, doi:10.1074/jbc.M304613200 (2003). 
31. Shigeoka, A., Gobel, R., Janatova, J. \& Hill, H. Neutrophil Mobilization Induced by Complement Fragments during Experimental Group-B Streptococcal (GBS) Infection. Am. J. Pathol. 133, 623-629 (1988).

32. Gilbert, H., Eaton, J., Hannan, J., Holers, V. \& Perkins, S. Solution structure of the complex between CR2 SCR 1-2 and C3d of human complement: An X-ray scattering and sedimentation modelling study. J. Mol. Biol. 346, 859-873, doi:10.1016/j.jmb.2004.12.006 (2005).

33. Li, K. et al. Solution Structure of the Complex Formed between Human Complement C3d and Full-length Complement Receptor Type 2. J. Mol. Biol. 384, 137-150, doi:10.1016/j.jmb.2008.08.084 (2008).

34. Zanotti, G. et al. Structure at 1.44 angstrom resolution of an N-terminally truncated form of the rat serum complement C3d fragment. Biochim. Biophys. Acta, Protein Struct. Mol. Enzymol. 1478, 232-238, doi:10.1016/S01674838(00)00040-6 (2000).

35. Isenman, D. E. \& van den Elsen, J. M. H. in Structural Biology of the Complement System (eds D. Morikis \& J.D. Lambris) Ch. 5, 111-142 (CRC Press, 2005).

36. Forneris, F. et al. Structures of C3b in Complex with Factors B and D Give Insight into Complement Convertase Formation. Science 330, 1816-1820, doi:10.1126/science.1195821 (2010).

37. Forneris, F. et al. Regulators of complement activity mediate inhibitory mechanisms through a common C3b-binding mode. EMBO J. 35, 1133-1149, doi:10.15252/embj.201593673 (2016).

38. Upadhyay, A. et al. Structure-function analysis of the C3 binding region of Staphylococcus aureus immune subversion protein Sbi. J. Biol. Chem. 283, 22113-22120, doi:10.1074/jbc.M802636200 (2008).

39. Burman, J. et al. Interaction of human complement with Sbi, a staphylococcal immunoglobulin-binding protein - Indications of a novel mechanism of complement evasion by Staphylococcus aureus. J. Biol. Chem. 283, 1757917593, doi:10.1074/jbc.M800265200 (2008).

40. Liu, Y. \& Eisenberg, D. 3D domain swapping: As domains continue to swap. Protein Sci. 11, 1285-1299, doi:10.1110/ps.0201402 (2002).

41. Kelly, S. M. \& Price, N. C. The Use of Circular Dichroism in the Investigation of Protein Structure and Function. Curr. Protein Pept. Sc. 1, 349-384, doi: 10.2174/1389203003381315 (2000).

42. Yang, P. et al. Engineering a long-acting, potent GLP-1 analog for microstructure-based transdermal delivery. Proc. Natl. Acad. Sci. USA 113, 4140-4145, doi:10.1073/pnas.1601653113 (2016).

43. Rousseau, F., Schymkowitz, J. \& Itzhaki, L. S. in Protein Dimerization and Oligomerization in Biology (ed Jacqueline M. Matthews) 137-152 (Springer New York, 2012).

44. de Jorge, E. et al. Dimerization of complement factor H-related proteins modulates complement activation in vivo. Proc. Natl. Acad. Sci. USA 110, 4685-4690, doi:10.1073/pnas.1219260110 (2013).

45. van Beek, A. et al. Factor H-Related (FHR)-1 and FHR-2 Form Homo- and Heterodimers, while FHR-5 Circulates Only As Homodimer in Human Plasma. Front. Immunol. 8, doi:10.3389/fimmu.2017.01328 (2017).

46. Lyubchenko, T., dal Porto, J., Cambier, J. C. \& Holers, V. M. Coligation of the B cell receptor with complement receptor type 2 (CR2/CD21) using its natural 
ligand C3dg: Activation without engagement of an inhibitory signaling pathway. J. Immunol. 174, 3264-3272, doi:10.4049/jimmunol.174.6.3264 (2005).

47. Lee, Y. et al. Complement component C3d-antigen complexes can either augment or inhibit $B$ lymphocyte activation and humoral immunity in mice depending on the degree of CD21/CD19 complex engagement. J. Immunol. 175, 8011-8023, doi:10.4049/jimmunol.175.12.8011 (2005).

48. Han, S. H. et al. Cellular Interaction in Germinal Centers - Roles of CD40 Ligand and B7-2 in Established Germinal Centers. J. Immunol. 155, 556-567 (1995).

49. Aversa, G., Punnonen, J., Carballido, J., Cocks, B. \& de Vries, J. CD40 ligandCD40 interaction in Ig isotype switching in mature and immature human B cells. Semin. Immunol. 6, 295-301, doi:10.1006/smim.1994.1038 (1994).

50. Zan, $\mathrm{H}$. et al. Induction of Ig somatic hypermutation and class switching in a human monoclonal $\lg \mathrm{M}^{+} \lg \mathrm{D}^{+} \mathrm{B}$ cell line in vitro: Definition of the requirements and modalities of hypermutation. J. Immunol. 162, 3437-3447 (1999).

51. Eris, J. M. et al. Anergic Self-Reactive B-Cells Present Self Antigen and Respond Normally to Cd40-Dependent T-Cell Signals but Are Defective in Antigen-Receptor-Mediated Functions. Proc. Natl. Acad. Sci. USA 91, 43924396, doi:10.1073/pnas.91.10.4392 (1994).

52. Tokunaga, M. et al. Down-regulation of CD40 and CD80 on B cells in patients with life-threatening systemic lupus erythematosus after successful treatment with rituximab. Rheumatology 44, 176-182, doi: 10.1093/rheumatology/keh443 (2005).

53. Desai-Mehta, A., Lu, L. J., Ramsey-Goldman, R. \& Datta, S. K. Hyperexpression of CD40 ligand by $B$ and T cells in human lupus and its role in pathogenic autoantibody production. J. Clin. Invest. 97, 2063-2073, doi:10.1172/JCl118643 (1996).

54. Kaneko, Y. et al. CD-40-mediated stimulated of B1 and B2 cells: Implication in autoantibody production in murine lupus. Eur. J. Immunol. 26, 3061-3065, doi:10.1002/eji.1830261236 (1996).

55. Tsoukas, C. D. \& Lambris, J. D. Expression of CR2/EBV Receptors on Human Thymocytes Detected by Monoclonal-Antibodies. Eur. J. Immunol. 18, 12991302, doi:10.1002/eji.1830180823 (1988).

56. Fischer, E., Delibrias, C. \& Kazatchkine, M. Expression of CR2 (the C3dg/EBV receptor, CD21) on normal human peripheral blood T lymphocytes. J. Immunol. 146, 865-869 (1991).

57. Levy, E. et al. Lymphocyte-T Expression of Complement Receptor-2 (Cr-2 Cd21) - a Role in Adhesive Cell Cell-Interactions and Dysregulation in a Patient with Systemic Lupus-Erythematosus (Sle). Clin. Exp. Immunol. 90, 235-244, doi:10.1111/j.1365-2249.1992.tb07935.x (1992).

58. Wagner, C. et al. The complement receptor 3, CR3 (CD11b/CD18), on T lymphocytes: activation-dependent up-regulation and regulatory function. Eur. J. Immunol. 31, 1173-1180, doi:10.1002/1521-4141(200104)31:4<1173::aidimmu1173>3.0.co;2-9 (2001).

59. Min, X. Y. et al. Expression and regulation of complement receptors by human natural killer cells. Immunobiology 219, 671-679, doi:10.1016/j.imbio.2014.03.018 (2014).

60. Zirlik, A. et al. CD40 ligand mediates inflammation independently of CD40 by interaction with Mac-1. Circulation 115, 1571-1580, doi:10.1161/CIRCULATIONAHA.106.683201 (2007). 
61. Prodeus, A. P. et al. A critical role for complement in maintenance of selftolerance. Immunity 9, 721-731, doi:10.1016/S1074-7613(00)80669-X (1998).

62. Birrell, L., Kulik, L., Morgan, B. P., Holers, V. M. \& Marchbank, K. J. B cells from mice prematurely expressing human complement receptor type 2 are unresponsive to T-dependent antigens. J. Immunol. 174, 6974-6982, doi: 10.4049/jimmunol.174.11.6974 (2005).

63. Quezada, S. A., Jarvinen, L. Z., Lind, E. E. \& Noelle, R. J. CD40/CD154 interactions at the interface of tolerance and immunity. Annu. Rev. Immunol. 22, 307-328, doi:10.1146/annurev.immunol.22.012703.104533 (2004).

64. Verbovetski, I. et al. Opsonization of apoptotic cells by autologous iC3b facilitates clearance by immature dendritic cells, down-regulates DR and CD86, and up-regulates CC chemokine receptor 7. J. Exp. Med. 196, 1553-1561, doi: 10.1084/jem.20020263 (2002).

65. Bajtay, Z., Speth, C., Erdei, A. \& Dierich, M. P. Cutting edge: Productive HIV-1 infection of dendritic cells via complement receptor type 3 (CR3, CD11b/CD18). J. Immunol. 173, 4775-4778, doi:10.4049/jimmunol.173.8.4775 (2004).

66. Suradhat, S. et al. Fusion of C3d molecule with bovine rotavirus VP7 or bovine herpesvirus type 1 glycoprotein $D$ inhibits immune responses following DNA immunization. Vet Immunol. Immunop. 83, 79-92, doi: 10.1016/s01652427(01)00369-5 (2001).

67. Mousavi, M. N. S. et al. The pathogenesis of Staphylococcus aureus in autoimmune diseases. Microb Pathog. 111, 503-507, doi:10.1016/j.micpath.2017.09.028 (2017).

68. Herbert, A. P., Uhrin, D., Lyon, M., Pangburn, M. K. \& Barlow, P. N. Diseaseassociated sequence variations congregate in a polyanion recognition patch on human factor $\mathrm{H}$ revealed in three-dimensional structure. J. Biol. Chem. 281, 16512-16520, doi:10.1074/jbc.M513611200 (2006).

69. Kulik, L. et al. Intrinsic B cell hypo-responsiveness in mice prematurely expressing human CR2/CD21 during B cell development. Eur. J. Immunol. 37, 623-633, doi:10.1002/eji.200636248 (2007).

70. Kulik, L., Chen, K. A., Huber, B. T. \& Holers, V. M. Human complement receptor type 2 (CR2/CD21) transgenic mice provide an in vivo model to study immunoregulatory effects of receptor antagonists. Mol. Immunol. 48, 883-894, doi:10.1016/j.molimm.2010.12.019 (2011). 


\section{Acknowledgements}

This research was supported by the Biotechnology and Biological Sciences Research Council Follow On Fund BB/N022165/1. A.A.W. was sponsored by a PhD studentship granted by Raoul and Catherine Hughes and the University of Bath Alumni Fund. R.W.D. was supported by a Medical Research Council GW4 Doctoral Training Partnership. B.G. and K.J.M. were funded by a Northern Counties Kidney Research Grant and Alexion Pharmaceuticals funded T.M.H.'s PhD studentship via Complement UK. K.J.M. also recognises the support from Kidney Research UK grant (RP-006-20270301). C.L.H. was funded by Newcastle University. The authors would like to acknowledge the team at the Diamond Light Source synchrotron (Oxfordshire, UK) for access to the $\mathrm{IO} 4$ beamline. Shaun Reeksting from the Material and Chemical Characterisation Facility ( $\mathrm{MC}^{2}$, University of Bath) is also thanked for his assistance with the mass spectrometry analyses.

\section{Author Contributions}

J.v.d.E, K.J.M., A.M., B.G.G. and A.A.W. designed the experiments. C.R.B. performed preliminary structural studies that lead to the discovery of the helix swap. A.A.W. performed the crystallisation and circular dichroism experiments. S.J.C. and A.A.W. reprocessed the crystallography data and refined the structures. R.W.D. produced the truncated Sbi-IV mutant and carried out the structural analyses and molecular modelling. A.G.W., B.A. and R.L.M. synthesised and characterised the linker and conducted initial linkage experiments. B.G.G. and A.A.W. performed the SPR experiments under the guidance of K.J.M. and with helpful discussions from C.L.H. who also analysed the data. L.K. completed the $\mathrm{Ca}^{2+}$ influx experiments. The $B$ cell activation flow cytometry experiments were performed by A.M. and K.W. with the assistance of I.P.M. J.v.d.E. and A.A.W. wrote the manuscript with valuable contributions from all the authors.

\section{Competing interests}

K.J.M. is a consultant for and receives funding or renumeration from Gemini Therapeutics Ltd., Freeline Therapeutics, MPM Capital and Catalyst Biosciences. 
C.L.H. has recently received consultancy or SAB payments from Freeline Therapeutics, Q32 Bio Inc., Roche, GlaxoSmithKline and Gyroscope Therapeutics and has received research funding from Ra Pharmaceuticals; all funds were donated to Newcastle University. T.M.H. is funded by Alexion Pharmaceuticals. All other authors declare no competing interests.

\section{Additional information}

Supplementary information for this publication is available online

Correspondence and requests for materials should be addressed to Ayla A. Wahid (A.A.Wahid@bath.ac.uk) and Jean M.H. van den Elsen

(J.M.H.V.Elsen@bath.ac.uk). 